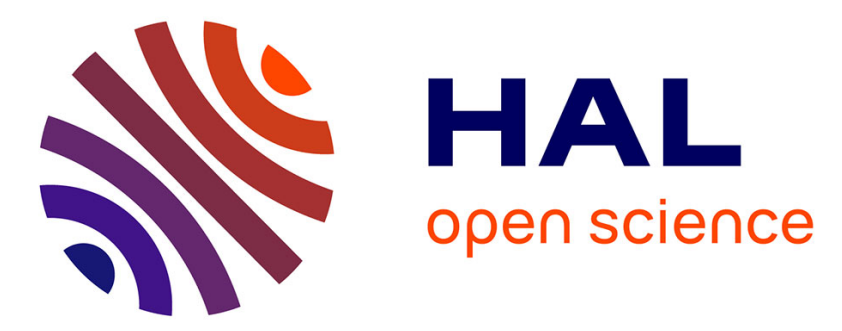

\title{
Thermo-Physics characterization of polypropylene/multi-walled carbon nanotube nanocomposites for rapid replication using hot embossing process
}

Mohamed Lakdhar Sahli, Thierry Barriere, Xavier Roizard

\section{To cite this version:}

Mohamed Lakdhar Sahli, Thierry Barriere, Xavier Roizard. Thermo-Physics characterization of polypropylene/multi-walled carbon nanotube nanocomposites for rapid replication using hot embossing process. Journal of Polymer Research, 2021, 28 (8), pp.305 (18). hal-03549370

\author{
HAL Id: hal-03549370 \\ https://hal.science/hal-03549370
}

Submitted on 31 Jan 2022

HAL is a multi-disciplinary open access archive for the deposit and dissemination of scientific research documents, whether they are published or not. The documents may come from teaching and research institutions in France or abroad, or from public or private research centers.
L'archive ouverte pluridisciplinaire HAL, est destinée au dépôt et à la diffusion de documents scientifiques de niveau recherche, publiés ou non, émanant des établissements d'enseignement et de recherche français ou étrangers, des laboratoires publics ou privés. 


\title{
THERMO-PHYSICS CHARACTERIZATION OF POLYPROPYLENE/MULTI-WALLED CARBON NANOTUBE NANOCOMPOSITES FOR RAPID REPLICATION USING HOT EMBOSSING PROCESS
}

\author{
Mohamed Sahli ${ }^{*}$, Thierry Barriere and Xavier Roizard \\ University Bourgogne-Franche-Comté, COMUE UBFC, Femto-ST Institute, Department of Applied Mechanics, \\ 24 Rue de l'Epitaphe, 25030 Besançon, France

\section{* Corresponding author} \\ Mohamed Sahli, \\ University Bourgogne-Franche-Comté, COMUE UBFC, Femto-ST Institute, Department of Applied Mechanics, \\ 24 Rue de l'Epitaphe, 25030 Besançon, France \\ Tel.: +033-3-81-40-28-54; Fax: +033-3-81-66-60-00 \\ e-mail: mohamed.sahli@femto-st.fr
}

\begin{abstract}
This study presents a comprehensive review of the thermophysical, rheological, and mechanical characteristics of nanocomposites reinforced with carbon nanotubes (CNTs). The high-loaded polypropylene (PP) nanocomposites with multi-walled carbon nanotube loadings ranging from $0.01 \mathrm{wt} . \%$ to $5 \mathrm{wt} . \%$ were elaborated via high-shear mixing using a twin-screw mixer. The structural and rheological properties of the neat polypropylene in the molten state and those of the elaborated composites were determined. The thermophysical properties of the nanocomposites were investigated via differential scanning calorimetry and thermogravimetric analysis. The mechanical properties were determined through quasi-static tensile testing at room temperature. The results clearly indicate that the incorporation of CNTs in a thermoplastic polymer matrix significantly improves the final thermophysical and mechanical properties of the nanocomposites, through excellent dispersion of CNTs in the thermoplastic matrix and an improvement in interfacial interaction. The produced nanocomposites were granulated and used in a hot embossing process to manufacture micro-structured components. These micro-shapes on the surface of a metal mould were successfully transferred to a CNTs/PP nanocomposite substrate.
\end{abstract}

Keywords: Carbon nanotube, Nanocomposites, Thermophysical analysis, Shear viscosities, CNTs aggregation. 


\section{Glossary}

$\begin{array}{ll}\text { CNTs } & \text { Carbon nanotubes } \\ \text { DSC } & \text { Differential scanning calorimetry } \\ \text { FFD } & \text { Used filament deposition } \\ G, & \text { Storage modulus } \\ G{ }^{\prime}, & \text { Loss modulus } \\ \text { MFI } & \text { Melt flow index } \\ \Delta H_{\text {cris }} & \text { Crystallization enthalpy } \\ \Delta H_{\mathrm{m}} & \text { Enthalpy of fusion } \\ \text { MWCNT } & \text { Multi-walled carbon nanotube } \\ \text { MWCNTs } & \text { Multi-walled carbon nanotubes } \\ \text { i-PP } & \text { Isotactic polypropylene } \\ \text { PP } & \text { Polypropylene } \\ \text { SEM } & \text { Scanning electron microscopy } \\ \text { TEM } & \text { Transmission electron microscopy } \\ \text { FTIR } & \text { Fourier transforms infrared } \\ \text { XRD } & \text { X-ray diffraction } \\ \text { TGA } & \text { Thermogravimetric analysis } \\ T_{\mathrm{c}} & \text { Crystallization temperature } \\ T_{\mathrm{m}} & \text { Melting temperature } \\ X_{\text {cris }} & \text { Degree of crystallinity } \\ \text { 3-D } & \text { Three-dimensional } \\ & \end{array}$




\section{Introduction}

Carbon nanotubes (CNTs) were attractive because of their well-known and singular properties such as high Young's modulus, high resistance, relatively high thermal conductivity, and electrical conductivity [1-5]. CNTs were widely used for reinforcement in the elaboration of nanostructured materials to improve their thermal, electrical, and mechanical behaviours. Their applications cover a broad range of medical, material, energy, and electronic devices [6-9]. Faramarzi et al. (2015) indicated that the wet process can elaborate a very homogeneous CNTs-asphalt binder. In addition, the addition of CNTs facilely improved the resistance to rutting and resistance to thermal cracking [10]. Zhou et al. (2017) have proposed molecular simulations to evaluate the thermomechanical characteristics of asphalt modified with CNTs [11]. They found that after the addition of CNTs, the asphalt exhibited considerable improvements in thermomechanical properties. Ameri et al. (2016) demonstrated that CNTs can improve both fatigue performance and fracture resistance of asphalt mixtures, in particular at high CNTs load levels [12].

CNTs nanocomposites were different from conventional materials and were excellent candidates for some common industrial applications, depending on the choice of matrix, the fillers to be added, the formulation to be developed, and the mode of their incorporation, with the aim of improving the interface polymer/loads. As an indication, Verma et al. (2015) successfully elaborated CNTs / PP nanocomposites by melt recirculation extrusion and obtained an EMI SE of $47 \mathrm{~dB}$ at $9.7 \mathrm{wt} \%$ CNTs loading [13]. Recently, scientists have become increasingly interested in the development of nanostructured composites loaded with CNTs developed in matrix materials such as thermoplastic polymers and elastomeric materials to improve their characteristics by exploiting the increased physical, mechanical, and electrical properties [14-16]. E. Neubauer et al. (2010) presented a review dedicated to carbon nanofibers and nanotubes as a reinforcement in metal-matrix composites to enhance mechanical and electrical properties [17]. Gupta et al. (2013) mainly studied the rheological characteristics of nanocomposites loaded with CNTs. They observed a significant increase in the mechanical properties in terms of storage and loss moduli when adding MWCNT to the poly(trimethylene terephthalate) matrix. In addition, they also found that the rheological percolation occurs at a lower load ( $\rho_{c}=0.25-1 \%$ by weight $)$ [18].

A uniform dispersion of CNTs without destroying their integrity and good interfacial bonding is required to achieve significant load transfer across the CNTs-matrix interface. J. Zhong et al. (2014) developed PP/CNTs nanostructured composites with a masterbatch dilution method using ultrasonic treatment. For nanostructured composites, Young's modulus and yield strength values increase and elongation value (i.e. at break) decreases with increasing CNTs content [19]. H. Xu et al. (2016) proposed to elaborate sandwich structure composites with CNTs film. They studied the evolution of flexural strength and inter-laminar shear strength in bending versus the number of CNTs film layers deposited in the optimization of their mechanical properties [20]. Gong et al. (2018) related that the improvement of the performance of asphalt at high temperature and their resistance to aging thanks to the addition of CNTs [21]. Mohamed et al. (2015) investigated the materials of multifunctional polybenzoxazine nanocomposites. In this study, they mainly synthesized a new multifunctional benzoxazine monomer Azo-COOH-Py BZ- featuring a carboxylic acid group, an azobenzene unit and a pyrene-moiety by the 
reaction of 4 [22]. In this study In this study they showed that the combination of carboxylic acid groups, photosensitive azobenzene units as well as CNTs makes it possible to effectively improve the carbon yields and the thermal stability of the polybenzoxazine matrices thanks to the TGA analyses.

A. Nadernezhad et al. (2019) investigated the extrusion of PLA/CNTs nanocomposites dedicated to additive manufacturing, and especially fused filament deposition [23]. They analysed the evolution of nanocomposites in terms of physical properties (crystallinity and cold crystallisation temperature) and mechanical properties (Young's modulus and tensile strength) versus CNTs content. Thermomechanical dimensions of 3-D printed nanocomposites were also investigated. They concluded that as the layer thickness increased during printing, mechanical strength significantly decreased and porosity increased due to shrinkage. Wang et al. (2018) showed that the resistance to aging of SBS modified asphalt was markedly improved by the addition of CNTs. They also highlighted the enhanced interfacial interaction of CNTs on the SBS binder [24]. Therefore, the development of nanocomposites based on polymer and CNTs leads to improved asphalt performance. X. Xu et al. (2020) investigated CNTs-reinforced nanocomposites ranging from $3 \mathrm{wt} \%$ to $15 \mathrm{wt} \%$ in a polyamide polymer matrix. The tensile specimens were manufactured by an injection moulding process using nanocomposites with welldispersed CNTs. The nanocomposites with the highest CNTs content (15 wt.\%) exhibited improvement in the storage and loss moduli, and the damping factor without saturation [25]. Mohamed et al. (2018) investigated CNTs nanocomposites based on polybenzoxazines and functional silica [26]. This study describes in detail the physical and chemical approaches that were adopted to develop PBZs incorporating silica and CNTs nanocomposites. Samy et al. (2020) were studied on the dispersion of single-walled carbon nanotubes and their energy storage using pyrene-functionalized tetraphenylethylene polybenzoxazine [27]. The nanocomposites produced have an high specific capacity and an excellent cycling stability. Another important result was that they exhibit a very low curing temperature. The development of nanocomposites loaded with uniformly dispersed CNTs was completely dissociated due to the effect of CNTs agglomeration in the polymer matrix [28-30]. N. Muralidharan et al. (2018) specifically used the high conductivity of CNTs to manufacture innovative electrochemical capacitors. These nanocomposites performed with an energy density near $3 \mathrm{mWh} / \mathrm{kg}$, an elastic modulus greater than $5 \mathrm{GPa}$, and mechanical strength greater than $85 \mathrm{MPa}$ [31]. M. J. Mahmoodi et al. (2018) used reinforced nanocomposites for specific damping properties. The evolution of the stored and dissipated energy was studied using various nanocomposite processing methods [32]. I. G. Tapeinos et al. (2012) studied piezo-resistivity effects for reinforced composites obtained by a resin transfer moulding process [33]. W. Donga et al. (2020) investigated the piezoresistive effect of CNTs-reinforced cementitious composites subjected to cyclic impact and compression strength tests. Increased electrical resistivity due to the pores and micro-cracks was reported. Furthermore, high resistance values were obtained with repeated impact due to the dense nanocomposite microstructures [34]. H. Lecocq et al. (2020) investigated different functional properties of nanocomposites with polypropylene and CNTs. The evolution of electrical and electromagnetic properties was investigated in a broad frequency range. A low percolation threshold of approximately $0.4 \mathrm{wt} . \%$ was obtained, with typical shielding performance reaching $90 \mathrm{~dB}$ between $50 \mathrm{MHz}$ and $18 \mathrm{GHz}$ [35]. Verma et al. (2015) studied the crystallization behaviour and the electrical characteristics of the nanocomposite made from PPCP loaded with MWCNTs. They found that MWCNTs acted as a nucleating agent and significantly affected 
crystallization parameters [13].

In the current study, thermoplastic matrix CNTs-loaded nanocomposites were investigated using a mechanical mixing process to enhance thermomechanical properties with content of CNTs from $0.1 \mathrm{wt} . \%$ to $5 \mathrm{wt} . \%$. The aim is to investigate the dispersion quality of CNTs as well as the morphological and structural analysis of polymer nanocomposites through scanning electron microscopy (SEM). The nanocomposite mechanical properties and fracture mechanism were analysed using tensile tests to determine their microstructure, Young's modulus, and tensile strength to better understand the stress-rupture strength. Thermal and rheological properties were investigated using thermogravimetric analysis (TGA) techniques and rheometer tests. The thermophysical, rheological, and mechanical properties were correlated with the morphology of the nanocomposites.

\section{Materials and Experimental Methods}

\subsection{Materials}

Thermoplastic polymeric materials were usually blended with a reinforcement or filler to enhance their flow properties and physical properties, to create new functional properties that were not provided by the matrix. The thermoplastic matrix used to develop the nanostructured composites was a commercially isotactic polypropylene (i-PP) supplied by Sabic Company ${ }^{\circledR}$. The polymer grade was adapted for processing by compounding and injection moulding processes. The density of polypropylene was $0.892 \mathrm{~g} / \mathrm{cm}^{3}$. The test conditions of the melt flow index (MFI) measurement were described in the ASTM D1238 standard. The MFI value was approximately $11 \mathrm{~g} / 10 \mathrm{~min}$, as obtained at $230{ }^{\circ} \mathrm{C}$ under a load of $2.16 \mathrm{~kg}$. The polypropylene properties were presented in Table 1.

The CN7000 ${ }^{\mathrm{TM}}$ multi-wall carbon nanotubes (MWCNTs) were provided by Nanocyl SA (Belgium). They have a diameter of 20-40 nm, a typical length of 1-10 $\mu \mathrm{m}$, a purity greater than $90 \%$, and a density of $1.30 \mathrm{~g} / \mathrm{cm}^{3}$. The fracture surfaces of nanocomposite samples were observed using a scanning electron microscope (SEM).

Table 1: Main characteristics of polypropylene

\begin{tabular}{lc}
\hline Density $\left[\mathrm{g} / \mathrm{cm}^{3}\right]$ & $0.892 \pm 0.001$ \\
\hline Glass transition temperature $\left[{ }^{\circ} \mathrm{C}\right]$ & $-10 \pm 1$ \\
\hline Melting temperature $\left[{ }^{\circ} \mathrm{C}\right]$ & $155 \pm 1$ \\
\hline Melt flow index $[\mathrm{g} / 10 \mathrm{~min}]$ & $11 \pm 1$ \\
\hline
\end{tabular}

\subsection{Nanocomposite fabrication method}

A twin-screw mixer equipped with double z-shaped blades was used to develop the nanostructured polymer composites with a high-shear mixing process characterized by better dispersion. In our tests, the mixing torques were measured using sensors in real time through process parameters. The description of the mixing procedure was as follows: before compounding, dry polymer preparation consisted of heating the granules in an oven at 80 ${ }^{\circ} \mathrm{C}$ for 24 hours to facilitate dispersion of CNTs. The dried pellets were inserted into a hot temperaturecontrolled chamber of the mixer at a rotational speed of $30 \mathrm{rpm}$ and a mixing temperature of $180{ }^{\circ} \mathrm{C}$. 
In the dispersion step, the CNTs were mixed with the xylene dispersion solvent in a beaker and then exposing this mixture of CNTs/xylene to $6 \mathrm{~h}$ of sonication, to obtain a uniform dispersion. Then, the CNTs were gradually added and mixed into the melted polypropylene for $30 \mathrm{~min}$. Upon cooling, the nanocomposite materials were granulated and used in the injection moulding process to produce homogeneous tensile test specimens. The highshear mixing method using a twin-screw mixer was used by Djoudi et al. (2015) for the elaboration of reinforced composites with high content of MWCNTs [36]. Fig.1 shows schematically the fabrication process for the CNTs/PP composites.

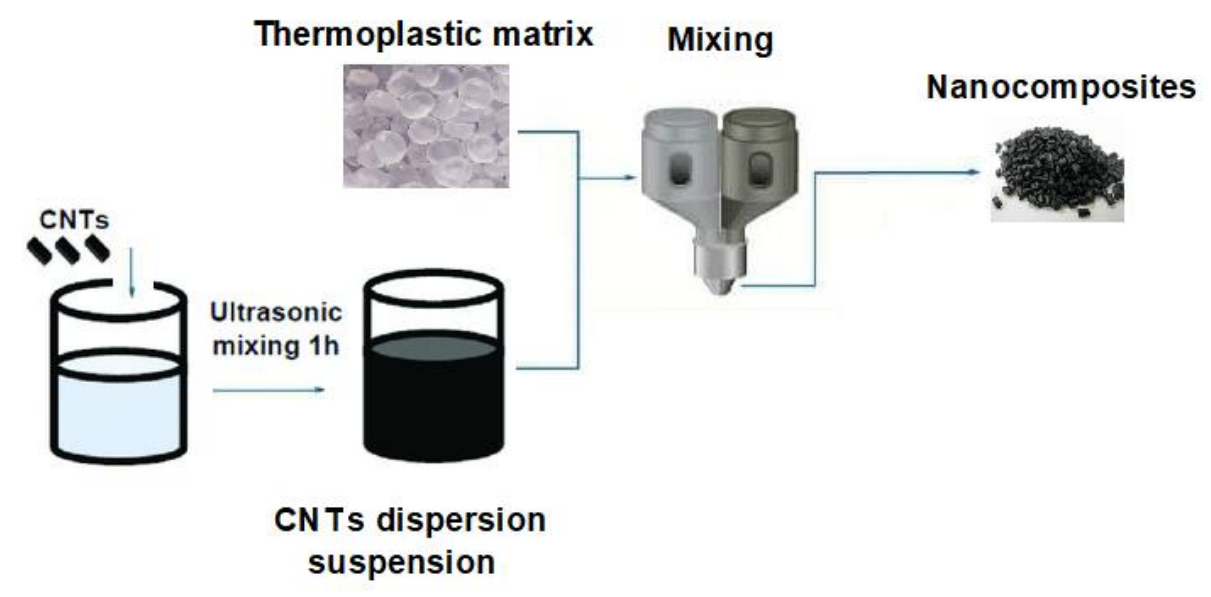

Fig.1. Diagram of CNT nanocomposite elaboration [36,37].

\subsection{Rheological characterization}

The rheological analyses of polypropylene and various nanocomposites with different mass fractions of CNTs were conducted under the thermal conditions of nanocomposite elaboration.

The steady shear rheological analysis was performed with cone-and-plate geometry and the cone angle was $2 \circ$. The data was collected over shear rate values ranging from $10^{-1} \mathrm{~s}^{-1}$ to $10^{2} \mathrm{~s}^{-1}$ at $180{ }^{\circ} \mathrm{C}$. The primary test was conducted using virgin polypropylene, without load, using mixing times ranging from 30 min to 180 min. The nanocomposite rheological analysis was performed in triplicate with percentages of CNTs ranging from 0.1 wt. $\%$ to $5 \mathrm{wt} . \%$. The steady shear rheological data were expressed as an average of the three measurements.

Dynamic shear measurements of the rheological properties of the polymer and nanocomposites were conducted with the HAAKE MARS III rheometer using two parallel plates (20 mm in diameter, $1 \mathrm{~mm}$ gap). The frequency

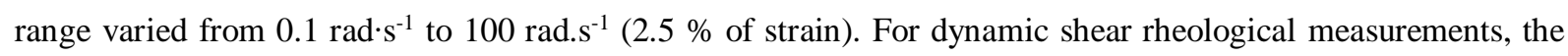
nanocomposites were tested in the linear viscoelastic deformation range. All rheological data were expressed as an average of three measurements.

\subsection{Thermal properties}

The effects of CNTs addition on the thermal properties of PP were measured by DSC analyses with standard test conditions (ASTM D3418-15) to determine the transition temperatures, enthalpies of fusion, and crystallization of materials. The thermal analysis was performed from $50{ }^{\circ} \mathrm{C}$ to $300{ }^{\circ} \mathrm{C}$ to quantify the melting and 
crystallization temperatures and the degree of crystallinity.

The kinetics of thermal degradation of virgin PP and functional polymer nanocomposites were studied using thermogravimetric analysis. Polymer degradation and stability were investigated using the standard method (ASTM D 5209-92). The weight of all samples tested was $10 \pm 1 \mathrm{mg}$. The thermogravimetric tests were conducted in air under thermo-oxidative conditions. All samples underwent a heating cycle between $25{ }^{\circ} \mathrm{C}$ and $500{ }^{\circ} \mathrm{C}$.

\subsection{Structure and morphology}

The morphology of the specimens was analysed using a scanning electron microscope type Evo50 SEM (Zeiss, Oberkochen, Germany) equipped with an energy dispersive X-ray detector (Oxford Instruments, Abingdon, United Kingdom). Then, the microstructure of the CNTs and the nanocomposites were also analysed by a JEOL JEM100-CX transmission electron microscope (TEM; JEOL, Japan). In his tests, a small amount of CNTs was dispersed before observation in toluene under ultrasonic vibration. Then, the well dispersed CNTs/toluene solution was poured directly onto a $\mathrm{Cu}$ grid and evaporated for a few minutes. Finally, the X-ray diffraction patterns (XRD) of different samples in virgin polymer and in nanocomposites were obtained using a Siemens D500 type diffractometer equipped with $\mathrm{Cu}-\mathrm{K} \alpha$ anode $(\lambda=0.1542 \mathrm{~nm})$ operating at $40 \mathrm{kV}$ and $30 \mathrm{~mA}$. Data was collected from 10 to $40^{\circ}$ at a scan rate of $0.02 \%$ s.

\subsection{FTIR characterization}

Fourier transforms infrared spectroscopy (FTIR) was a powerful non-destructive method to determine and quantification the chemical properties and structure of nanocomposites. Fourier transform infrared (FTIR) spectra were obtained with a PerkinElmer spectrometer in transmission mode and scanned using $4 \mathrm{~mm} / \mathrm{s}$ at resolution of $2 \mathrm{~cm}$ over a wavenumber region of $400-4000 \mathrm{~cm}^{-1}$.

\subsection{Uniaxial tensile testing}

The tensile test specimens were produced by an injection moulding process. The injection moulding press was equipped with multi-cavity tooling for tensile test specimen shapes. The injection moulding pressure, the mould temperature, and injection temperature were selected as $80 \mathrm{MPa}, 25{ }^{\circ} \mathrm{C}$, and $200{ }^{\circ} \mathrm{C}$, respectively. Nanocomposite test specimens with loadings from $0.01 \mathrm{wt} . \%$ to $5 \mathrm{wt} \%$ were produced. To determine the strength specifications of the reinforced composites by tensile tests, the ASTM D638 standard was applied. The quasi-static tensile tests were performed under displacement-controlled conditions at a constant crosshead rate of $1 \mathrm{~mm} / \mathrm{min}$ at room temperature. The tensile tests were performed five times to evaluate the reproducibility of the experiments.

\subsection{Hot embossing process replication}

In the manufacturing process, a hot embossing press was used to produce micro-structured devices with PP/CNTs composites. The composites were formed with a dedicated micro-structured die mould cavity. The hot embossing press used an applied force of $8 \mathrm{kN}$, a forming temperature of $200{ }^{\circ} \mathrm{C}$, and an imposed holding time of $2 \mathrm{~min}$. 


\section{Results and discussion}

\subsection{Nanocomposites elaboration}

Mixing torque versus mixing time and loading of the elaborated functional nanocomposites loaded with 0.01 wt. $\%$ to 5 wt. $\%$ of CNTs were plotted in Fig.2a and $2 \mathrm{~b}$. With the imposed mixing temperature of $180{ }^{\circ} \mathrm{C}$, the neat PP did not degrade during mixing, which corresponds to the initial DSC test results.

The introduction of dry solid PP and CNTs into the twin-screw mixer before mixing produced very high mixing torque values. For each CNTs content level, the peak height values increased up to $200 \%$ compared with the torque curve values after $5 \mathrm{~min}$. A stabilisation torque curve was produced for $30 \mathrm{~min}$, corresponding to a premixed phase. Using the internal mixer and melt extrusion, the PP was softened by heating in the mixing chamber, resulting in a gradual decrease in the mixing torque. As a result, effective and intensive mixing began after $15 \mathrm{~min}$. In these graphs, the mixing operation was completed when the mixing torque reaches a stable value over time. These results show that the mixing torque increases gradually and that the fluidity decreases with the addition of CNTs. After approximately 15 min, stable composite mixing was reached, and the mixing curves indicate the significant effect of the CNTs. The maximum final mixing torque was $8 \mathrm{~N} \cdot \mathrm{m}$, obtained at $180 \mathrm{~min}$ with 5 wt.\% of CNTs. According to the literature, this was the mixing torque value used for the standard injection moulding process to manufacture injection test specimens.

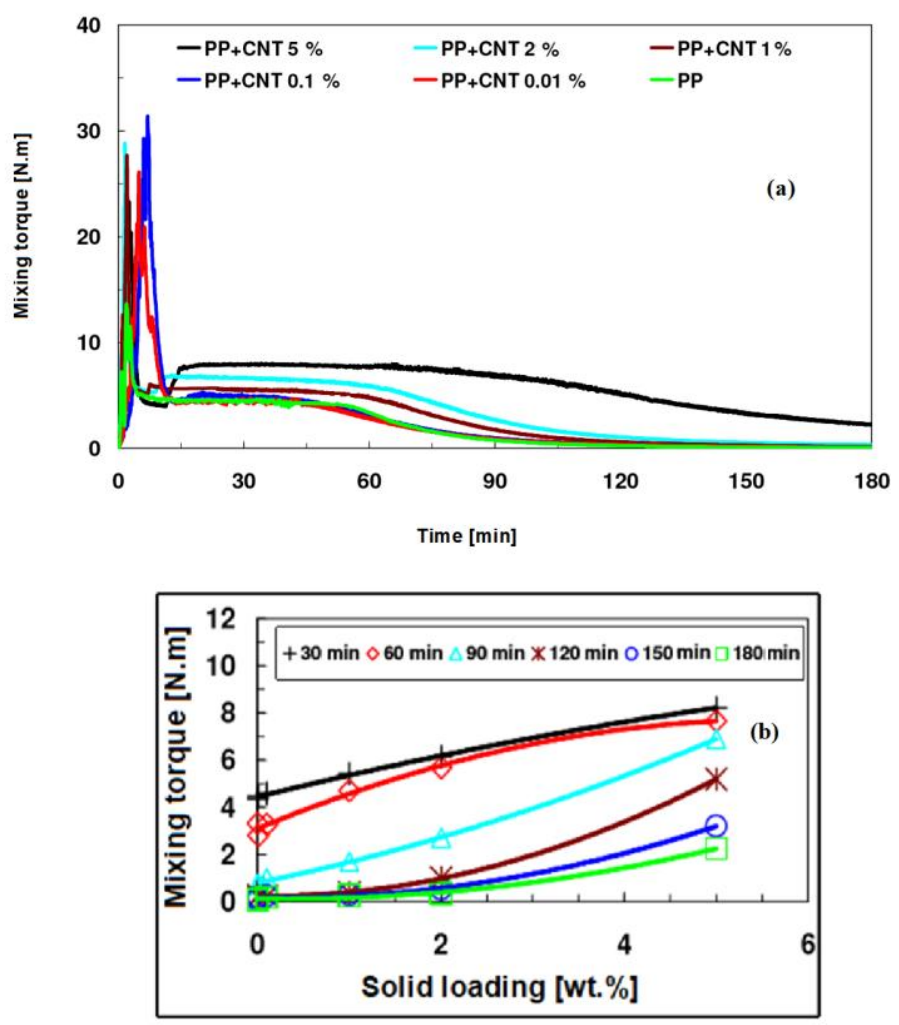

Fig.2. (a) Mixing torque evolution curves for virgin PP and functional nanocomposites vs. time (obtained at 180 ${ }^{\circ} \mathrm{C}$ over $180 \mathrm{~min}$ ) and (b) Mixing torque evolution curves vs wt.\% of CNTs at different mixing times (obtained at $\left.180{ }^{\circ} \mathrm{C}\right)$ 


\subsection{Structure and morphology observation of nanocomposites}

The dispersion of CNTs in a polymer matrix was always one of the most important issues that must be taken into account for the development of high performance CNTs nanocomposites. Indeed, a homogeneous dispersion of CNTs and a strong interaction at the interface between CNTs and polymer matrix can very effectively improve both the mechanical, thermal and electrical characteristics of nanocomposites [38]. SEM images illustrating the morphologies of nanocomposites containing 3 wt.\% of CNTs were shown in Fig.3. The CNTs have a diameter of approximately $100 \pm 20 \mathrm{~nm}$. Fractured surface observations of highly loaded nanostructured composites (3 wt.\% of CNTs) indicate that the CNTs distribution was homogeneous on the thermoplastic matrix surface. Due to the dissolution of the polymer surface, the CNTs appear clear with similar morphologies. The elevated structures clearly indicate their largely homogeneous distribution into the thermoplastic polymer matrix. Therefore, the better dispersion of CNTs can result in more efficient transfer of loads imposed on CNTs nanocomposite materials. It can also result in an higher effective filling volume compared to that of virgin CNTs, which further contributes to improving the elastic response of CNTs nanocomposites materials (see Fig.4).
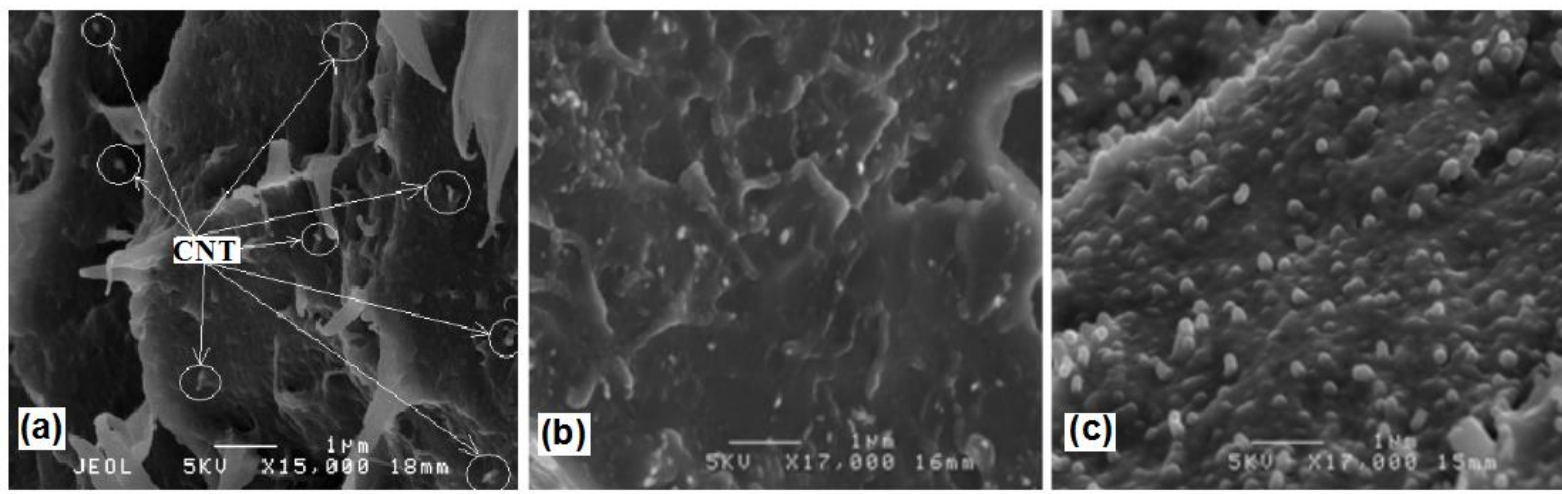

Fig.3. SEM micrograph of CNTs/PP nanocomposite after mixing stage: (a) 0.1 wt.\% CNTs, (b) 2 wt.\% CNTs and (c) 5 wt. $\%$ CNTs.
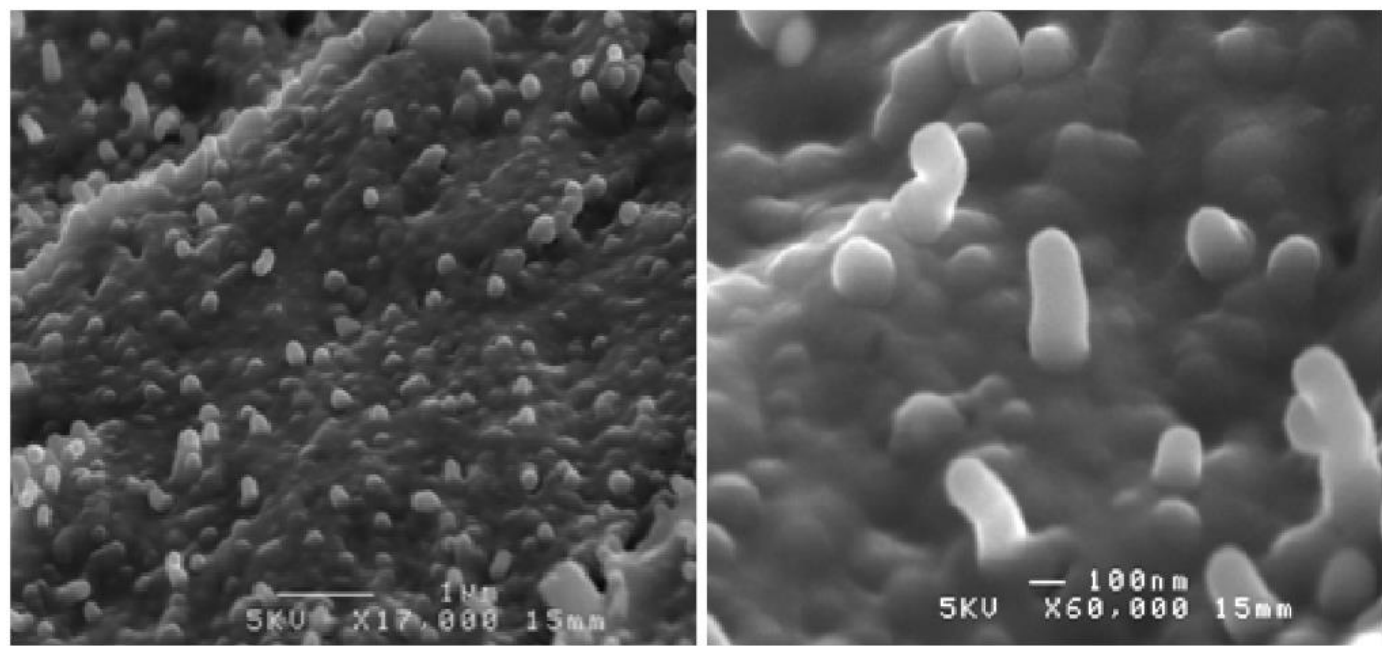

Fig.4. SEM micrograph of 5 wt.\% CNTs/PP nanocomposite. 


\subsection{TEM characterization}

TEM images of raw CNTs and nanocomposites materials with different magnification were related in Fig.5. Measurements were carried-out mainly to estimate the average diameter and length of the CNTs. The mean diameter measured was of the order of 20 and $40 \mathrm{~nm}$ while the length was around of tens of microns. It was observed that the CNTs were in perfect condition and presented a smooth surface with a graphitized structure (see Figs. 5a, 5b). In contrast, for the nanocomposite materials of PP/CNTs clearly had a thin layer of PP coating of the order of 4 to $6 \mathrm{~nm}$ on the surface of the CNTs. The PP/CNTs nanocomposite shows a bilayer structure with an inner core of CNTs and an amorphous and very rough outer surface (see Figs. 5c, 5d).
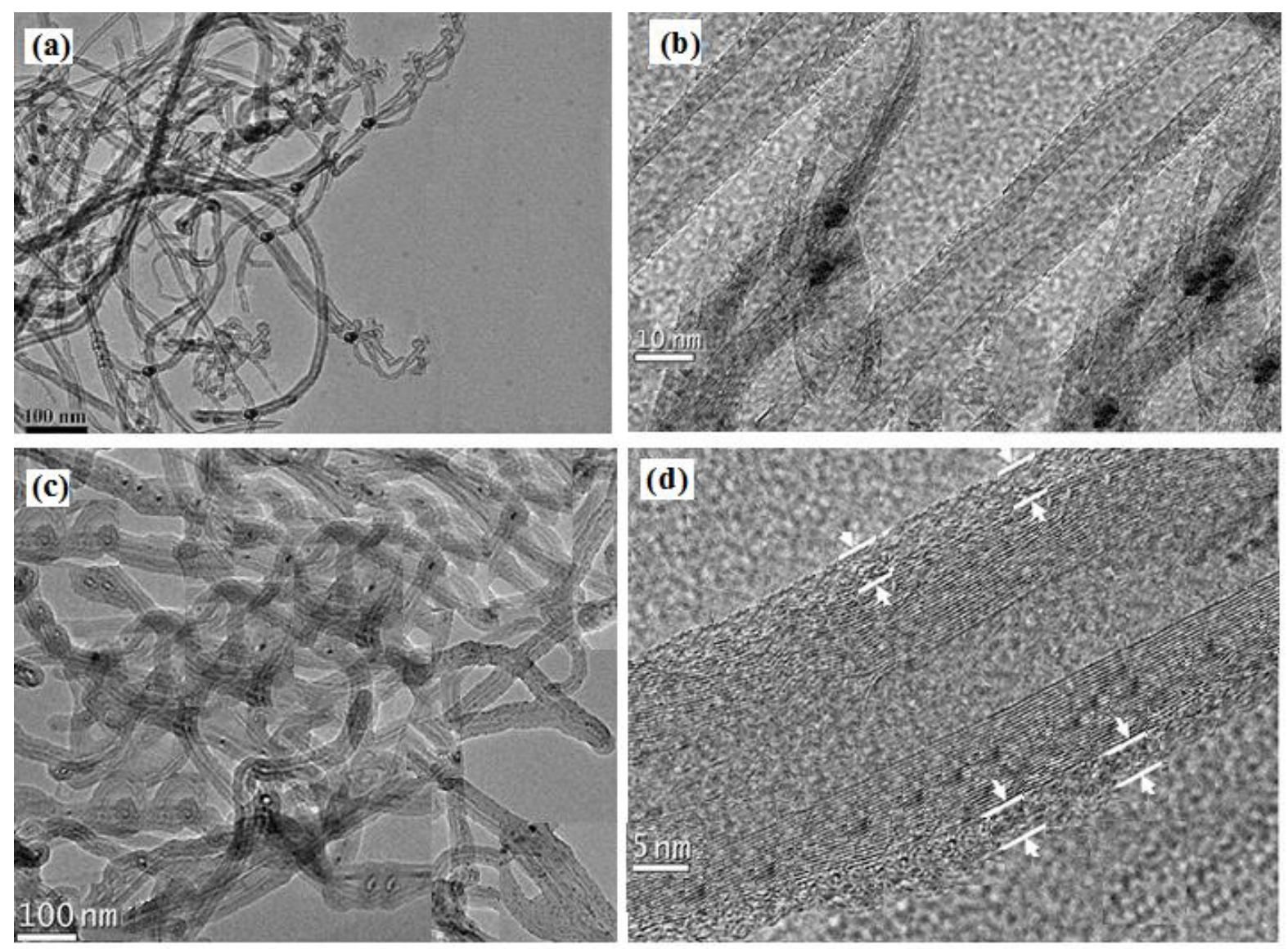

Fig.5. TEM images of (a) and (b) CNTs and (c) and (d) PP/CNTs nanocomposites

\subsection{FTIR characterization}

Comparisons in FTIR spectra of virgin PP and its representative CNTs/PP nanocomposites with different loading rates were respectively illustrated in Fig. 6a. Very strong absorption peaks were clearly observed for virgin PP at 3300-2800 $\mathrm{cm}^{-1}$, certainly attributed to symmetrical and asymmetrical $\mathrm{CH} 2$ or $\mathrm{CH} 3$ vibrations. However, the specific interactions between the polymer matrix and the CNTs play an very important role. In the thermoplastic polypropylene matrix, MWCNTs were relatively better dispersed by donor-acceptor conjugation (see Figs. 3 and 4). This resulted in progressively high melting and crystallisation temperatures with increasing loading rates in the PP-based nanocomposites (see Fig.13). At the same time, the intensity of the absorption peaks at $3300-2800 \mathrm{~cm}^{-1}$ greatly increased with the incorporation of CNTs (see Fig.6a). 

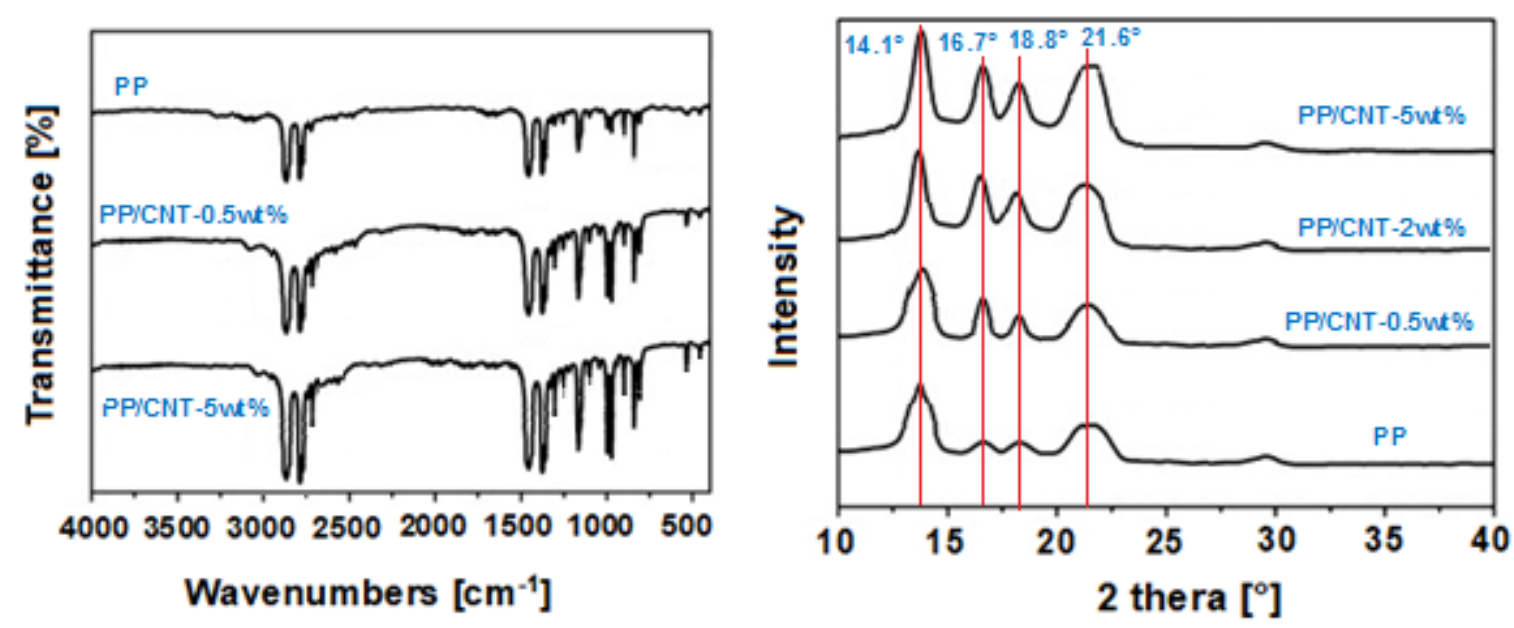

Fig. 6. (a) FTIR spectra of PP and PP/CNTs nanocomposites and (b) typical XRD patterns for PP matrix and PP/CNTs nanocomposites.

Figure $6 \mathrm{~b}$ illustrates typical XRD patterns for virgin PP and CNTs/PP nanocomposite materials with different loading rates of CNTs. The $2 \theta$ peaks were observed at $14.1^{\circ}, 16.8^{\circ}, 18.6^{\circ}, 21.1^{\circ}$ and $21.8^{\circ}$ corresponding to the (110), (040), (130), (111) and (041) planes. This observation confirms that the PP crystals were in $\alpha$ form in all the samples tested, that is to say the most common phase and also the most stable. Obviously, no structural change was observed in the nanocomposites following the addition of CNTs. This result was not surprising because it has already been observed in other works where they indicated that CNTs mainly nucleate $\alpha$ form PP crystals $[39,40]$. The presence of either $\beta$ or $\gamma$ form PP crystals can therefore be excluded because crystals of $\beta$ form have rather strong diffraction peaks around $16.2^{\circ}$ and $21.2^{\circ}$ while crystals of $\gamma$ form were often characterized by peak at $20.1^{\circ}[41,42]$.

\subsection{Rheological characterization}

Understanding the rheological behaviour of functional CNTs/PP composites in the molten state provides fundamental knowledge about their behaviour during mould filling in an injection moulding process, and a better understanding of the correlation between the material structure and the thermophysical properties of the nanocomposites.

Flow curve evolution for virgin PP was illustrated in Fig.7. The sample was elaborated by twin-screw mixing with virgin PP. The curve analysis shows an change in rheological behaviour of nanocomposites versus mixing time. Nanocomposites initially have a non-Newtonian behaviour similar to that virgin PP. This behaviour suddenly changes to Newtenian behaviour from a slightly longer mixing time beyond $60 \mathrm{~min}$.. The composite changes from a pseudo-plastic fluid to an approximately Newtonian fluid. The reduction in shear viscosity toward a limit value can probably be explained by the progressive de-structuring of the polymer chains. The results agree with the measurements of the mixing couples illustrated in Fig.2a, and suggest that the mixing time induces substantial changes in the rheological behaviour of PP. 


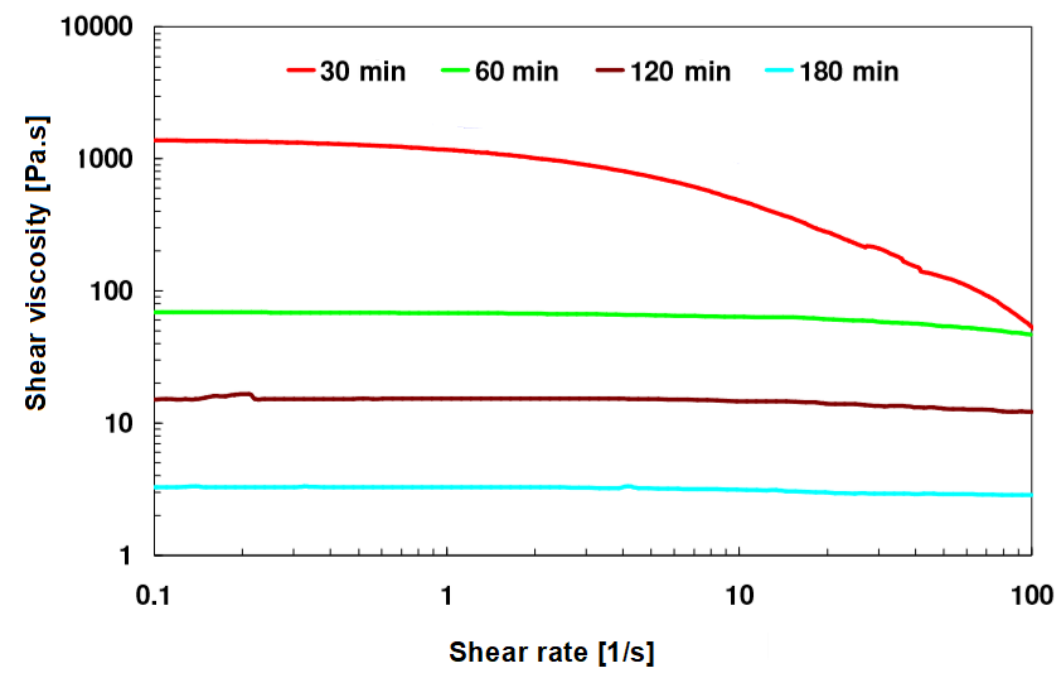

Fig.7. Evolution of flow curves as shear viscosity versus shear rate for virgin $\mathrm{PP}$ at $180{ }^{\circ} \mathrm{C}$ with different mixing times

The effect of CNTs loading rate on the nanocomposite rheological behaviour was shown in Fig.8. It was observed that the shear viscosity of the most heavily loaded batch of nanocomposites was higher than that of virgin PP and lightly loaded composites. The rheological behaviour of the nanocomposites loaded with 0.05 wt.\% to 5 wt.\% of CNTs were approximately pseudo-plastic, with shear viscosity decreasing with increasing shear rate. Flow curves (log-log plot of shear viscosity vs. shear rate) exhibit a shear-thinning behaviour, approximated by the Herschel-Bulkley model [43]. This behaviour could be attributed to strong interactions between the thermoplastic polymer matrix and the CNTs. These interactions could inhibit the chain flexibility and ultimately increase the shear viscosity of the nanocomposites.

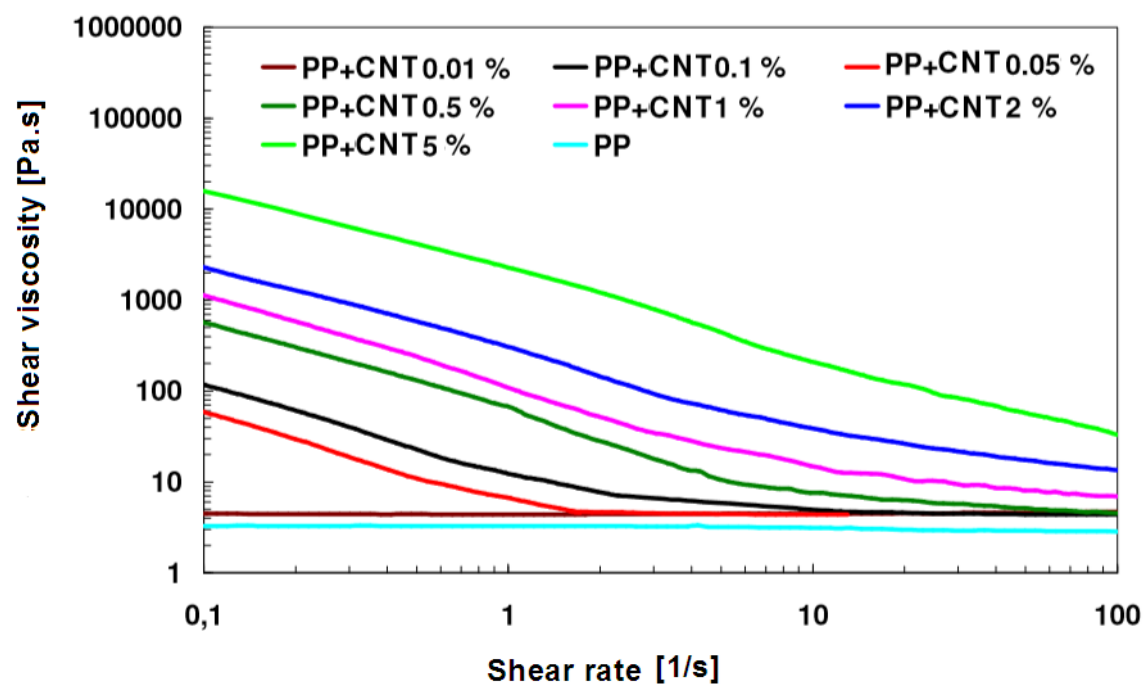

Fig.8. Shear viscosity of nanocomposites with 0.01 wt.\% to 5 wt. $\%$ of CNTs vs. shear rate obtained at $180{ }^{\circ} \mathrm{C}$ with 180 min mixing time. 
The storage modulus $\left(G^{\prime}\right)$ and the loss modulus $\left(G^{\prime \prime}\right)$ for neat PP and PP/CNTs nanocomposites with CNTs contents of $0.01-5 w t . \%$ versus the applied frequency were plotted in Fig.9. They widely perceptible that nanotubes have a perceptible effect on the viscoelastic behaviour. The $G^{\prime}$ and $G^{\prime \prime}$ values increase continuously with frequency. Furthermore, the loss modulus values were greater than the storage modulus values, corresponding to viscous behaviour [44].

In the $50 \mathrm{~Hz}$ to $100 \mathrm{~Hz}$ range, there was a similarity in the qualitative behaviour of $G^{\prime}$ and $G^{\prime \prime}$ moduli values for the various nanocomposites, indicating that the movements of the polymer chains were not affected by the addition of CNTs. However, the storage modulus values at lower frequencies depend on the addition of CNTs. In this range, the rheological properties can be considered to be in a relaxation phase [18]. Loss modulus and storage modulus show similar frequency dependence, as shown in Fig.9b. Increasing CNTs content leads to a transition from convex to concave curves. At sufficiently high content, the elastic modulus tends to level off as frequency goes to zero.
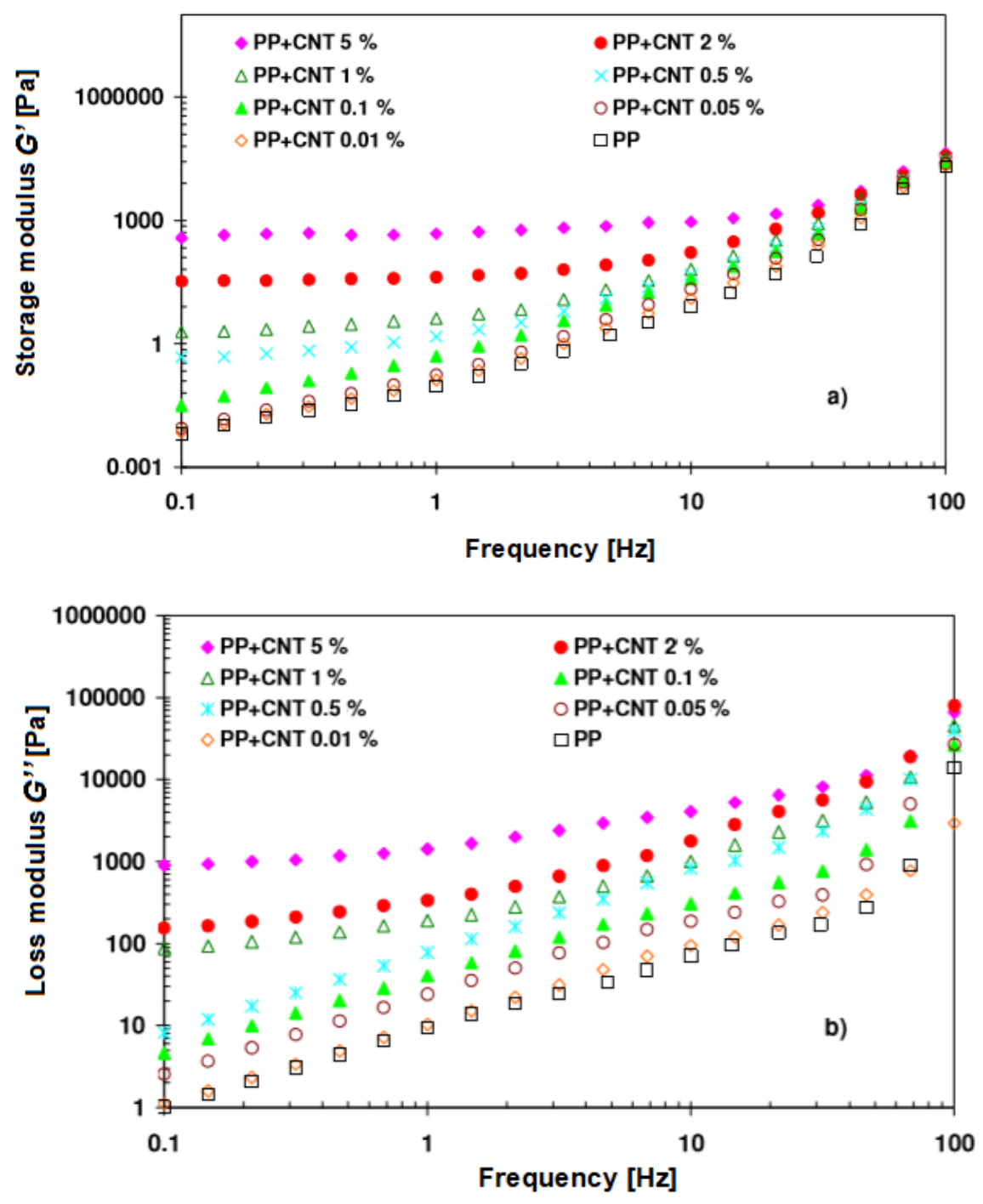

Fig.9. Evolution of storage modulus $G$ ' and loss modulus $G$ ” versus applied frequency and CNTs content for various nanocomposites (at $180{ }^{\circ} \mathrm{C}$, and a strain value of $2.5 \%$ ) 
The evolution of the storage and loss moduli as a function of the mass fraction of CNTs for frequencies between $10^{-1}$ and $10^{2} \mathrm{~Hz}$ was plotted for comparison, as shown in Fig.10. The formation of a percolating network of CNTs with a liquid-solid transition can be deduced from the comparison between the elastic and viscous moduli according to the content of CNTs and different frequencies [45]. It was observed that the values of the two moduli increase slightly with increasing CNTs content. The values of $\tan (\delta)$ directly obtained from the ratio of $G$ ” to $G$ ' can also be used to analyse the viscoelastic behaviour of CNTs/PP nanocomposites. For virgin PP and nanocomposites with different CNTs contents, the viscous behaviour was clearly dominant, which results in $\tan (\delta)>1$, as $G$ ” $>G^{\prime}$. This phenomenon was mainly explained by the fact that with the gradual increase in the CNTs content in nanocomposites, the interactions between the nanotube/nanotube and also between the nanotubes/polymer increase appreciably $[18,46]$. This result can lead mainly to the formation of a CNTs network with an interconnected structure. It can also limit the mobility of the polymer chains. This finding was clearly observable from our TEM images (see Fig.5), where the nanotubes intersect at random and form a lattice structure.
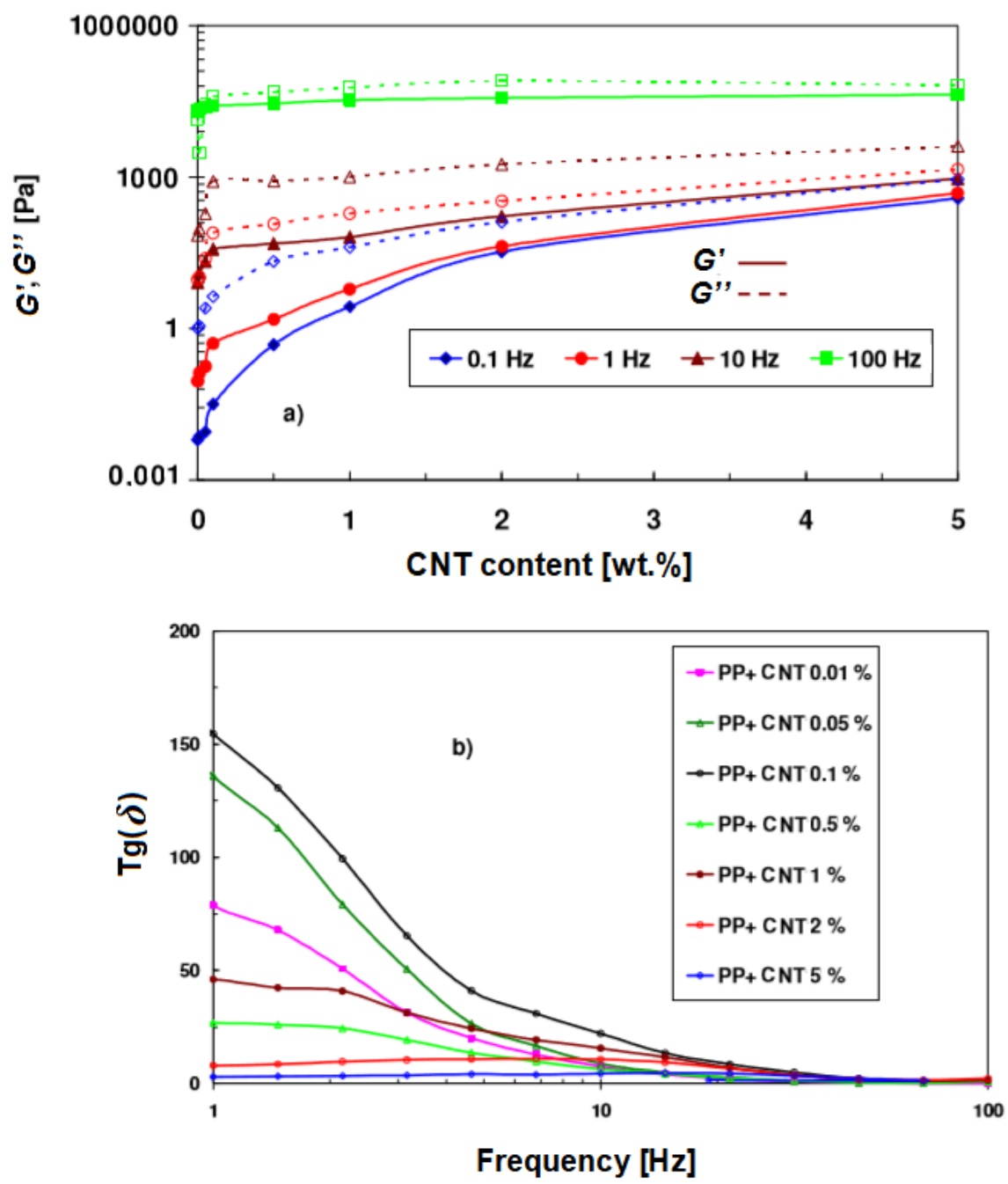

Fig.10. Variation of viscoelastic modulus with CNTs content and frequency (content of CNTs (0.01-5 wt.\%)) 
Table 2. Values of slope in the low frequency region determined from the plots of storage modulus $\left(\mathrm{G}^{\prime}\right) / \mathrm{loss}$ modulus $\left(\mathrm{G}^{\prime \prime}\right)$ /shear viscosity $\left(\eta_{0}\right)$ vs frequency $(\omega)$ for PP/CNTs nanocomposites.

\begin{tabular}{cccc}
\hline \multirow{2}{*}{ Sample designation } & \multicolumn{3}{c}{ Slope calculated from } \\
& G' $[$ Pa] & G” $[$ Pa] & $\boldsymbol{\eta}_{0}[$ Pa.s] \\
\hline PP & 0.11 & 1.1 & 3.2 \\
PP-0.01wt\%. & 0.17 & 1.6 & 4.5 \\
PP-0.05wt\%. & 0.27 & 2.4 & 60.1 \\
PP-0.1wt\%. & 0.78 & 4.8 & 100.5 \\
PP-0.5wt\%. & 1.94 & 8.7 & 503.2 \\
PP-1wt\%. & 62.1 & 95.4 & 670.5 \\
PP-2wt\%. & 136.2 & 287.2 & 1250 \\
PP-5wt\%. & 675.7 & 975.2 & 20100 \\
\hline
\end{tabular}

\subsection{Homogeneity analysis and thermal analysis}

The homogeneity of the CNTs/PP composite was analysed through thermogravimetric analysis (TGA). The dispersion quality of CNTs in the thermoplastic matrix was studied in a temperature range of $25-00{ }^{\circ} \mathrm{C}$. The TGA result was illustrated in Fig.11; it was observed that the TGA curves drop from $400{ }^{\circ} \mathrm{C}$, corresponding to the beginning of the PP polymer degradation. Temperatures between $400{ }^{\circ} \mathrm{C}$ and $450{ }^{\circ} \mathrm{C}$ cause the final PP decomposition. The curve results of three sequential TGA tests of the same composite material $(0.1$ wt.\% of CNTs) were almost identical. Based on the analyses, the melt mixing processing induced homogenous dispersion; the CNTs were well-dispersed in the polymer matrix.

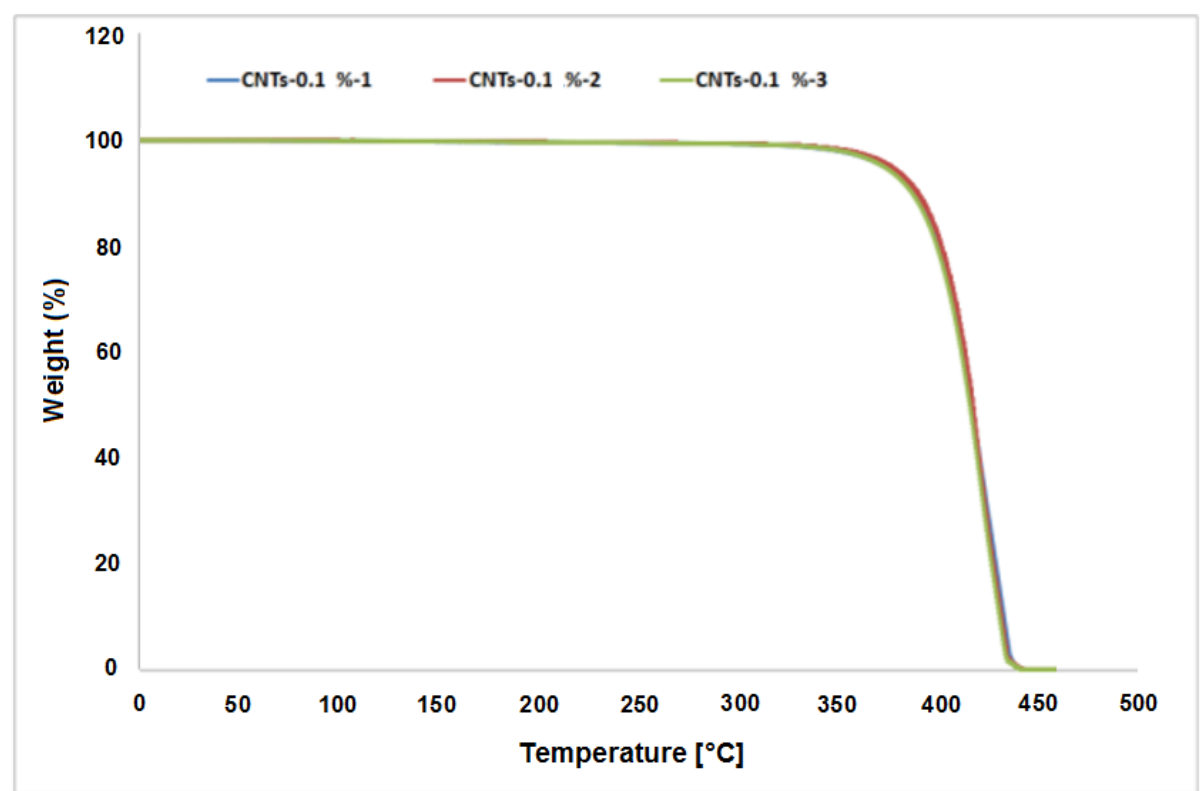

Fig.11. Mass loss evolution of the nanocomposite loaded with $0.1 \mathrm{wt} \% \%$ of CNTs 
The thermal properties of virgin PP and nanostructured composites were by studied by thermal analysis (TGA and DSC) in the temperature range of $20{ }^{\circ} \mathrm{C}$ to $500{ }^{\circ} \mathrm{C}$. Fig. 12 presents the resulting TGA curves indicating the thermal degradation of virgin PP and nanocomposites containing 0.01 wt.\% to 5 wt.\% of CNTs. The tests were conducted in a controlled atmosphere using argon gas. The TGA experiments were performed three times to verify and evaluate reproducibility. For the CNTs/PP nanocomposites, the TGA graph results show an initial weight loss with the oxidation of the amorphous carbon materials existing in the CNTs/PP composites at temperatures above $350{ }^{\circ} \mathrm{C}$. The oxidation can also be attributed to decomposition of the thermoplastic matrix. The PP was completely degraded at $430{ }^{\circ} \mathrm{C}$. It was observed that some nanocomposites exhibited higher degradation temperatures than virgin polypropylene. The introduction of CNTs improved the thermal stability of the nanocomposites. The marked improvement could be attributed to high thermal stability of the CNTs and the interaction between the thermoplastic matrix and the CNTs.

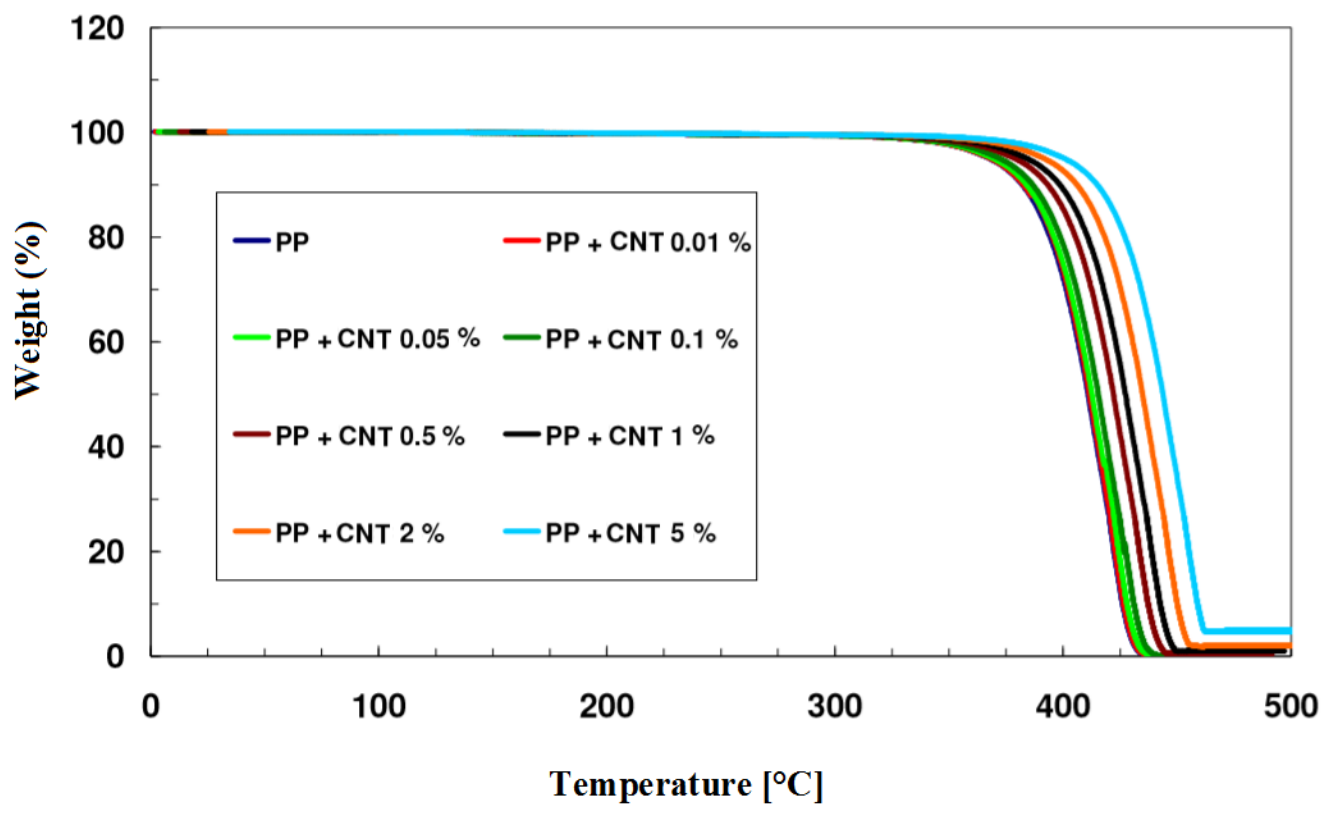

Fig.12. TGA thermograms of virgin $\mathrm{PP}$ and $\mathrm{CNTs} / \mathrm{PP}$ nanocomposites from $20{ }^{\circ} \mathrm{C}$ to $500{ }^{\circ} \mathrm{C}$ (content of $\mathrm{CNTs}$ (0.01-5 wt.\%)).

A summary of the temperatures $\mathrm{T}_{5 \%}$ and $\mathrm{T}_{20 \%}$ which correspond to a mass loss of $5 \mathrm{wt} \%$ and $20 \mathrm{wt} \%$ obtained from the ATG curves for PP/CNTs nanocomposites produced at different mass fractions of CNTs (0.01 to $5 \mathrm{wt} \%$, see Table 3).

\begin{tabular}{|c|c|c|c|c|c|c|c|c|}
\hline $\begin{array}{l}\text { Mass loss } \\
\text { ratio [\%] }\end{array}$ & PP & $\begin{array}{c}\text { PP-CNTs } \\
0.01 \%\end{array}$ & $\begin{array}{c}\text { PP-CNTs } \\
0.05 \%\end{array}$ & $\begin{array}{c}\text { PP-CNTs } \\
0.1 \%\end{array}$ & $\begin{array}{c}\text { PP-CNTs } \\
0.5 \%\end{array}$ & $\begin{array}{c}\text { PP-CNTs } \\
1 \%\end{array}$ & $\begin{array}{c}\text { PP-CNTs } \\
2 \%\end{array}$ & $\begin{array}{c}\text { PP-CNTs } \\
5 \%\end{array}$ \\
\hline $\mathbf{T}_{5 \%}$ & 428.84 & 429.37 & 430.70 & 433.64 & 439.94 & 445.32 & 452.74 & 461.67 \\
\hline $\mathbf{T}_{\mathbf{2 0} \%}$ & 422.40 & 422.97 & 424.43 & 427.55 & 433.50 & 438.80 & 446.30 & 455.20 \\
\hline
\end{tabular}

Table 3. Evolution of the temperatures versus a mass loss of 5\% and $20 \%$ for different nanocomposites produced at different mass fractions of CNTs from to 0.01 to $5 \mathrm{wt} \%$. 
DSC analysis was used to determine the melting and crystallization temperatures $\left(T_{\mathrm{m}}\right.$ and $\left.T_{\mathrm{c}}\right)$ of both virgin polymer and different nanocomposites; the DSC curve results were presented in Fig.13. Fig. 13a illustrates the sensitivity of the crystallization temperature to the addition of small quantities of CNTs. Crystallization temperature increases significantly with addition of CNTs in the nanocomposites. The $T_{\mathrm{c}}$ of virgin PP was measured at $95{ }^{\circ} \mathrm{C} ; T_{\mathrm{c}}$ reaches $120{ }^{\circ} \mathrm{C}$ for nanocomposites with $5 \mathrm{wt} \%$ of CNTs. Surprisingly, there was no improvement in the melting temperature of the nanocomposites. The $T_{\mathrm{c}}$ was approximately $155{ }^{\circ} \mathrm{C}$ for neat $\mathrm{PP}$ and different nanostructured composites. Small variations were measured compared to virgin PP, estimated at \pm $3{ }^{\circ} \mathrm{C}$, as shown in Fig.13b.
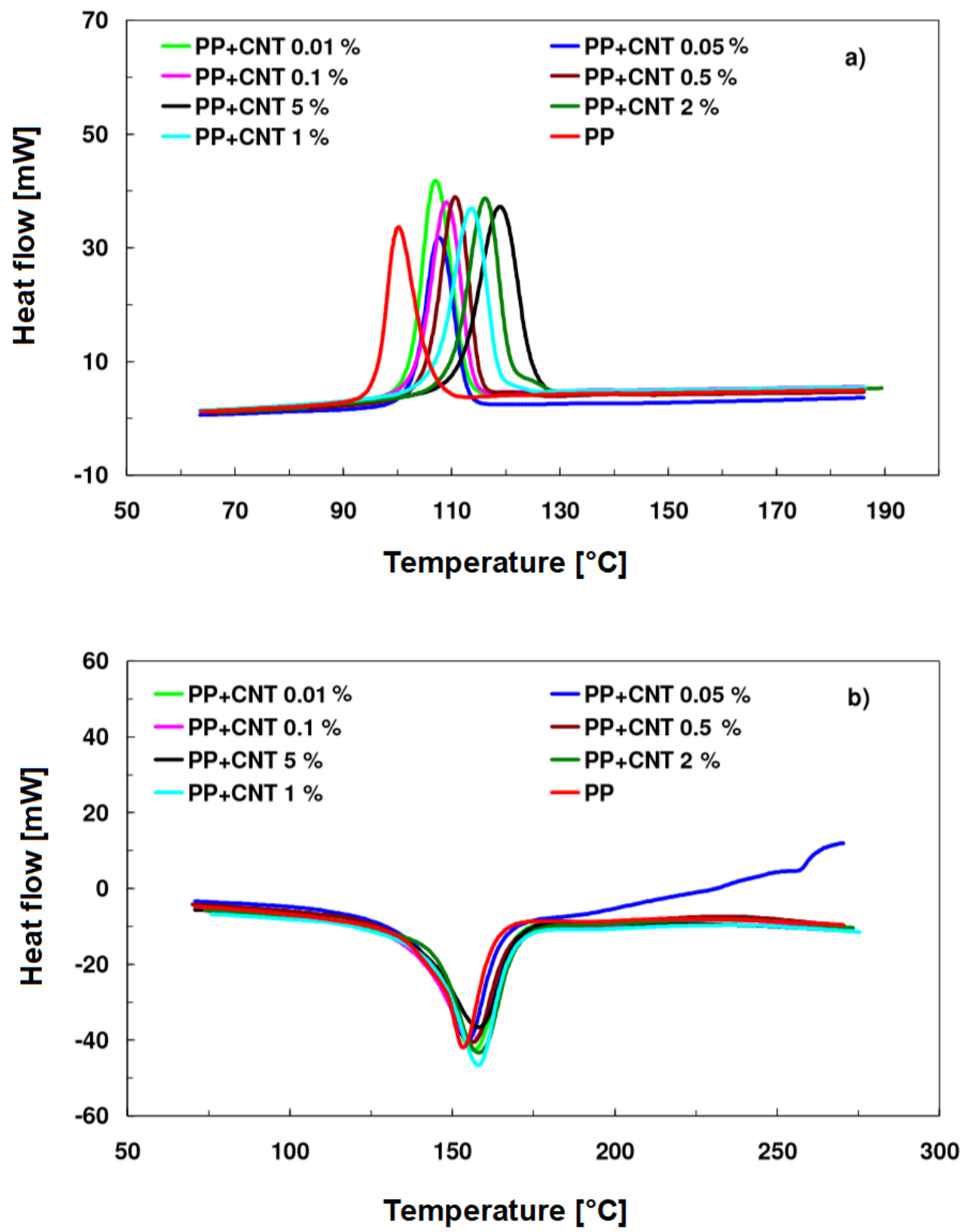

Fig.13. DSC analysis of PP/CNTs nanocomposites - content of CNTs (0.01-5 wt.\%): (a) crystallization temperature and (b) melting temperature 
The addition of small amounts of CNTs into the virgin PP also showed that enthalpy of fusion $\left(\Delta H_{\mathrm{m}}\right)$ increases slightly with increasing mass fraction of CNTs. Nevertheless, considering the contribution of batch variabilities recorded from five representative analyses, the increase was negligible. The thermos-physical parameters of PP/CNTs nanocomposites studied were related in Table 4. The experimental results show that the thermosphysical values of CNTs/PP nanocomposites materials increase distinctly with increasing CNTs content.

The crystallization enthalpy ( $\Delta H_{\text {cris }}$ ) of virgin PP was measured at $88.80 \mathrm{~J} / \mathrm{g}$, and the addition of CNTs slightly increased $\Delta H_{\text {cris. }}$ However, the degree of crystallinity $\left(X_{\text {cris }}\right)$ increases with increasing CNTs content in the nanocomposites to a maximum value of $77.49 \%$ for nanocomposite samples containing 5 wt.\% of CNTs, compared to $52.48 \%$ for virgin PP. This may be associated with the percolation threshold concentration of highloaded composites; variations were also reported in the melting temperature (see Fig.14). This proves that the addition of CNTs was very beneficial in increasing the performance in terms of thermal resistance and dimensional stability of the nanocomposites.
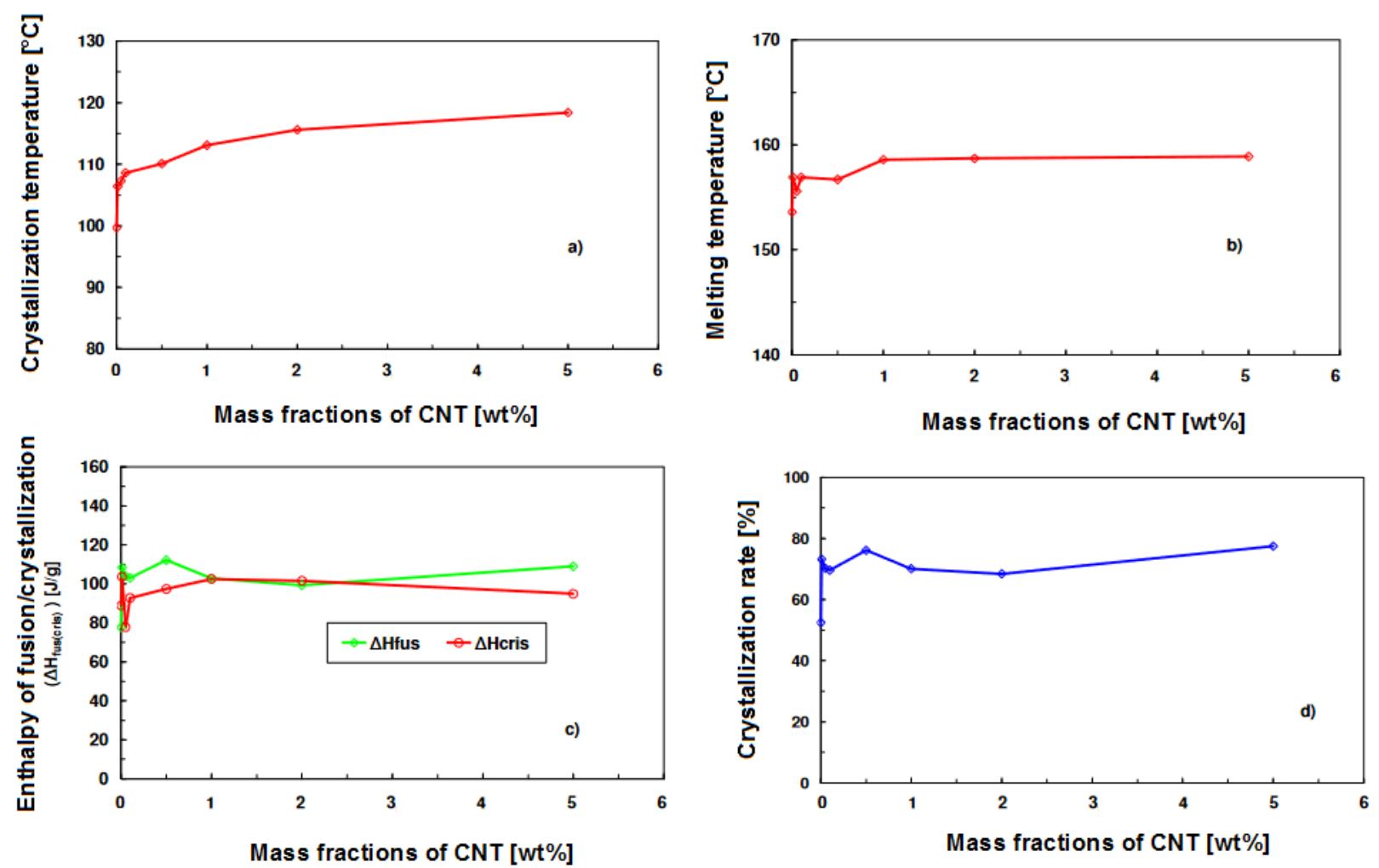

Fig.14. Thermal parameters of nanocomposites versus the mass fraction of CNTs: (a) crystallization temperature (Tc), (b) melting temperature $\left(\mathrm{T}_{\mathrm{f}}\right)$, (c) enthalpies crystallization $\left(\Delta \mathrm{H}_{\text {cris }}\right)$ - melting $\left(\Delta \mathrm{H}_{\text {fus }}\right)$, and (d) crystallinity rate $\left(\mathrm{X}_{\mathrm{c}}\right)$. 
Table 4. Thermophysical parameters of PP/CNTs nanocomposites (content of CNTs (0.01-5 wt.\%))

\begin{tabular}{cccccc}
\hline $\begin{array}{c}\text { CNTs content } \\
(\boldsymbol{\%})\end{array}$ & $\begin{array}{c}\boldsymbol{\Delta} \boldsymbol{H}_{\mathrm{m}} \\
{[\mathbf{J} / \mathbf{g}]}\end{array}$ & $\begin{array}{c}\boldsymbol{\Delta} \boldsymbol{H}_{\text {cris }} \\
{[\mathbf{J} / \mathbf{g}]}\end{array}$ & $\begin{array}{c}\boldsymbol{X}_{\text {cris }} \\
{[\boldsymbol{\%}]}\end{array}$ & $\begin{array}{c}\boldsymbol{T}_{\mathrm{m}} \\
{\left[{ }^{\circ} \mathbf{C}\right]}\end{array}$ & $\begin{array}{c}\boldsymbol{T}_{\mathbf{c}} \\
{\left[{ }^{\circ} \mathbf{C}\right]}\end{array}$ \\
\hline 0.0 & 77.68 & 88.8 & 52.48 & 153.6 & 99.7 \\
0.01 & 108.37 & 103.69 & 73.21 & 156.9 & 106.4 \\
0.05 & 103.88 & 77.72 & 70.22 & 155.6 & 107.3 \\
0.1 & 102.99 & 92.74 & 65.65 & 156.9 & 108.6 \\
0.5 & 112.14 & 97.36 & 76.15 & 156.7 & 110.1 \\
1 & 102.73 & 102.47 & 70.11 & 158.6 & 113.1 \\
2 & 99.27 & 101.56 & 68.44 & 158.7 & 115.6 \\
5 & 108.96 & 94.87 & 77.49 & 158.9 & 118.4 \\
\hline
\end{tabular}

\subsection{Mechanical properties of nanocomposites}

To investigate the effects of the addition of CNTs on the mechanical properties of nanocomposites, dumbbellshaped tensile test specimens were produced by an injection moulding process. The influence of CNTs dispersion on the mechanical properties of composite materials was illustrated in Fig.15. Quantification of the Young's modulus and the ultimate strength values was performed for composites with different contents of CNTs. The functional composites show a noticeable increase in tensile strength and modulus, approximately 118 $\%$ and $38 \%$, respectively, for PP/CNTs with 5 wt.\% compared to virgin PP. The elongation at break of the nanocomposites decreases approximately $10 \%$ with increasing CNTs content compared to neat PP. The dispersion of CNTs can significantly improve mechanical properties of the final nanocomposites. The mechanical properties investigation has been devoted to the elastic modulus and the yield strength. Experimental results of the elastic modulus and the yield strength versus CNTs content were plotted in Fig.16. The data points in Fig.16 correspond to average values obtained from five sequential tensile specimen tests. The Young's modulus and yield strength measured experimentally were approximately $1.57 \mathrm{GPa}$ and $68 \mathrm{MPa}$, respectively. Both Young's modulus and yield stress values show the impact of increasing CNTs content on the elastic properties of the nanocomposite. Increase in elastic properties was observed as a function of CNTs content. S. Acierno et al. (2017) investigated the specific mechanical properties of PP/CNTs nanocomposites [47]. The evolution of the Young's modulus, yield strength, and ductility exhibits a linear relationship with the CNTs content. Our results were conformed to the results of S. Acierno et al. (2017). 


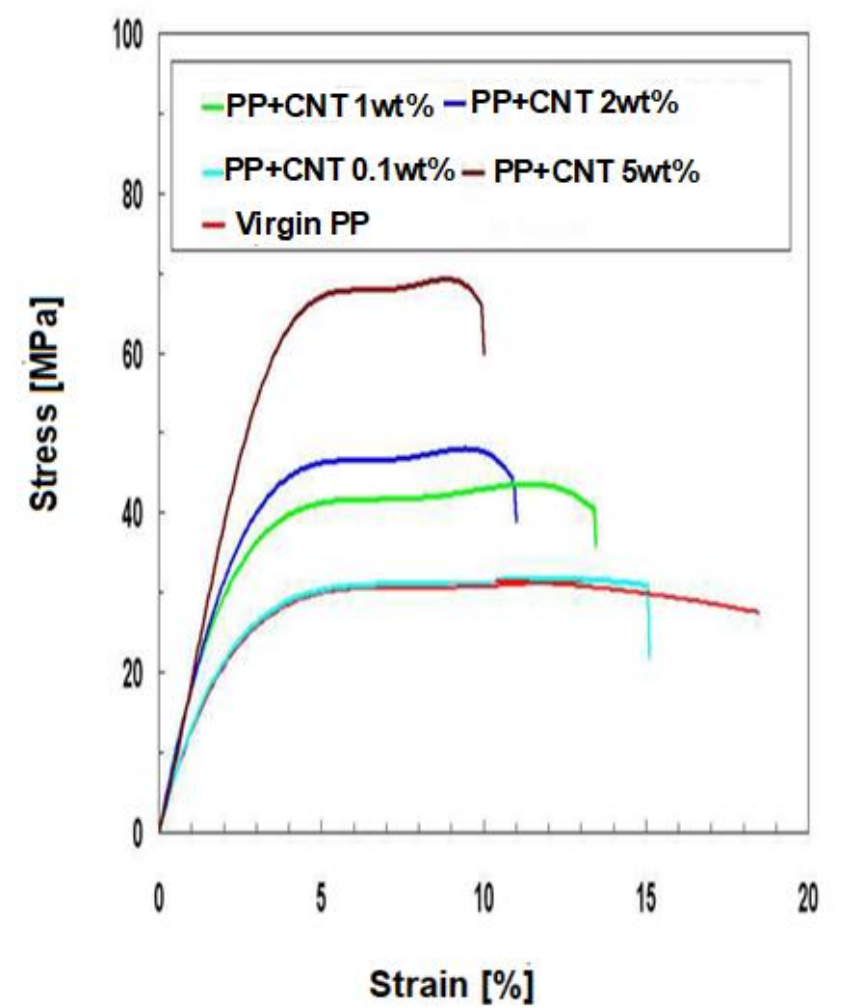

Fig.15. Stress-strain curves for virgin polymer and nanocomposites with different CNTs contents (0.01-5 wt.\%) at room temperature

The evolution of the Young's modulus, the tensile strength, and the elongation at break for different CNTs contents were summarized in Table 5. Interactions between the CNTs and the thermoplastic polymer matrix result in an improvement of elastic properties such as the Young's modulus and tensile strength.

Table 5. Properties of neat polymer and nanocomposites with different CNTs content (0.01-5 wt.\%)

\begin{tabular}{ccc}
\hline $\begin{array}{c}\text { CNTs content } \\
(\%)\end{array}$ & $\begin{array}{c}\text { Young's modulus } \\
{[\mathbf{G P a}]}\end{array}$ & $\begin{array}{c}\text { Yield strength } \\
{[\mathbf{M P a}]}\end{array}$ \\
\hline 0.0 & $1.37 \pm 0.02$ & $31.06 \pm 0.02$ \\
0.1 & $1.43 \pm 0.03$ & $31.37 \pm 0.03$ \\
1.0 & $1.57 \pm 0.05$ & $43.36 \pm 0.04$ \\
2.0 & $1.63 \pm 0.04$ & $47.53 \pm 0.02$ \\
5.0 & $1.89 \pm 0.03$ & $68.90 \pm 0.02$ \\
\hline
\end{tabular}



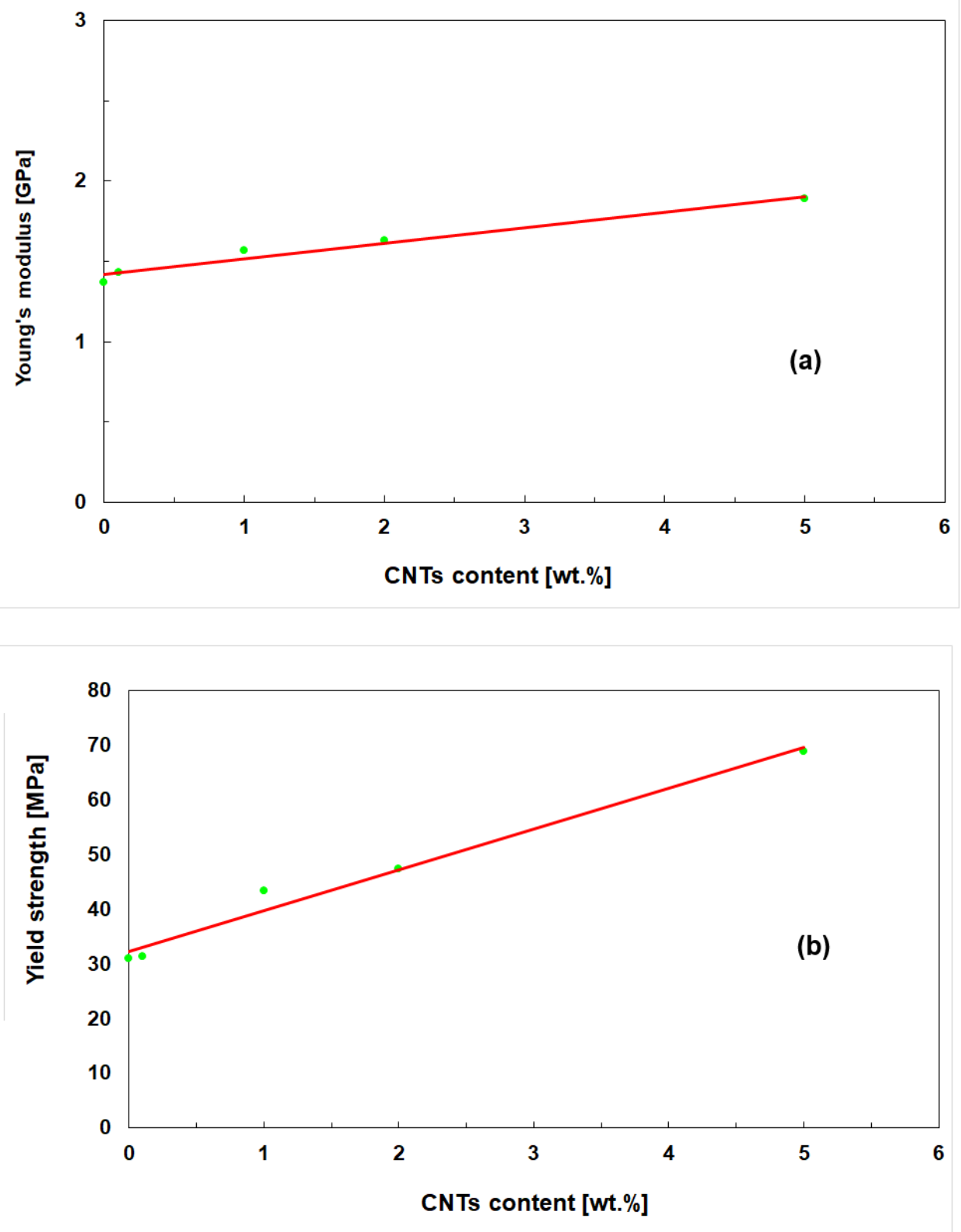

Fig.16. Mechanical properties evolution of CNTs/PP nanocomposites versus the CNTs content at room temperature: (a) Young's modulus and (b) Yield strength - the plots include a linear fit of the mechanical data listed in Table 5

\subsection{Hot embossing results}

3-D topographic contours of replicas produced by hot embossing under the same conditions with different CNTs contents were shown in Fig.17. The filling rate of the die mould cavities as significantly linked to the weight fraction of CNTs in the nanocomposite, which directly correlates with the measured rheological properties. 

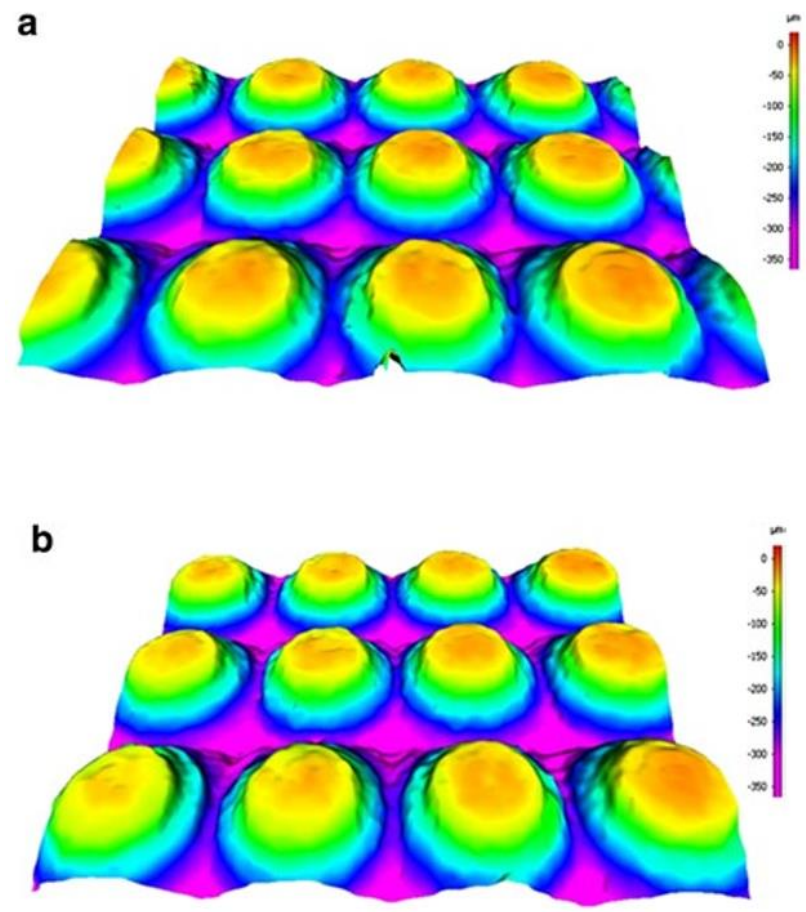

Fig.17. 3-D topographic contours of nanocomposite replicas with two different CNTs contents (a) 0.1 wt.\% and (b) 1 wt.\% obtained by hot embossing process

The filling rate evolution of the die mould cavities as a function of the CNTs content was illustrated in Fig. 18. It was observed that the replicas with low weight fractions of CNTs fill the mould cavities more effectively, while higher weight fractions of CNTs produce replicas of poor quality. This was directly related to the viscosity of the composites.

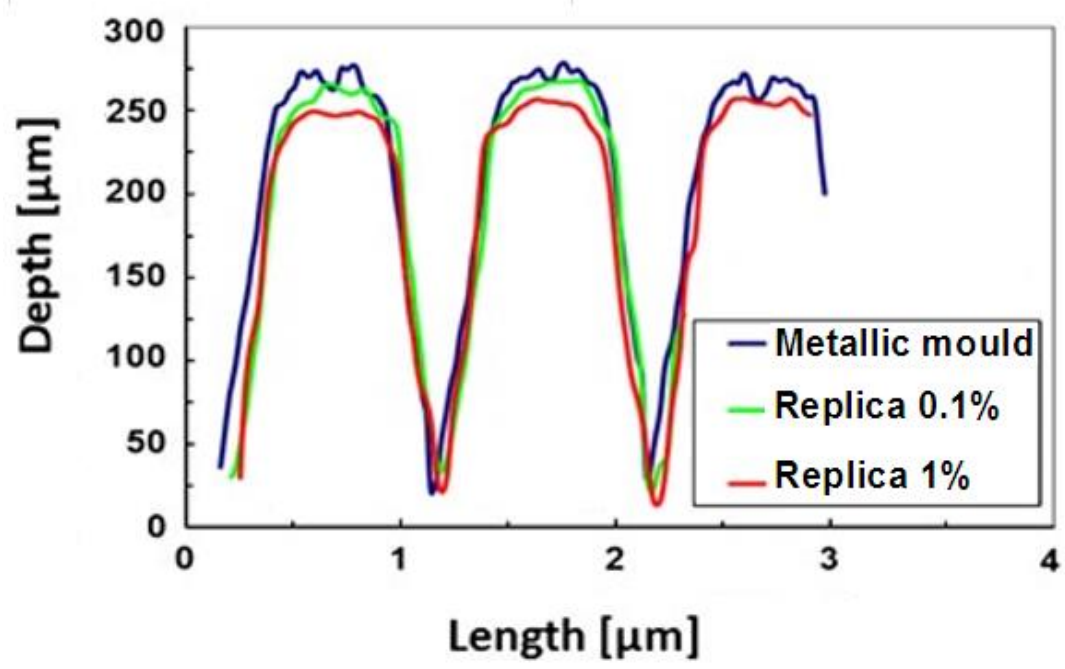

Fig.18. 2-D profiles of nanocomposite replicas using different weight fractions of CNTs, obtained by hot embossing process 


\section{Conclusions}

Incorporation of CNTs into virgin PP substantially increases thermal stability, rheological characteristics, tensile properties, and fracture toughness of nanostructured composites, while the draw-down ratio (drawability) significantly decreases. The following conclusions can be drawn:

$\circ \quad$ The storage and loss moduli values of nanocomposites increased gradually with increasing frequency for CNTs contents in a large frequency range from $0.1 \mathrm{rad} \cdot \mathrm{s}^{-1}$ to $100 \mathrm{rad} \cdot \mathrm{s}^{-1}$. In the high-frequency range, there was no significant difference in either storage modulus or loss modulus values for the nanocomposites, indicating that the movements of the polymer chains were not affected. The values of both moduli in the low-frequency range depend significantly on the addition of CNTs. At sufficiently high concentrations, the elastic modulus tends to level off as frequency goes to zero.

- The morphological characterization carried-out by SEM then by TEM showed a good dispersion with a uniform distribution of the CNTs in the thermoplastic PP matrix, which meant that the melt mixing process was a very efficient technique for the elaboration of the PP/CNTs nanocomposites.

- The most significant improvements in mechanical properties for the nanocomposite at the highest CNTs content (5 wt.\%): the ultimate tensile strength increased $118 \%$, the Young's modulus increased $38 \%$, and the fracture toughness increased $214 \%$. These significant changes in thermomechanical characteristics result from good dispersion of CNTs in the thermoplastic polymer matrix and improved interfacial interaction.

- Generally, nanocomposite replicas with micro-structured patterns were successfully transferred to substrates. The final quality was significantly affected by the weight fraction of CNTs in the nanocomposite. The weight fraction can be improved by increasing the shaping temperature of nanocomposites with a high content of CNTs.

\section{REFERENCES}

1. Arabani M, Faramarzi M (2015) Characterization of CNTs-modified HMA's mechanical properties. Constr. Build. Mater.83:207-215

2. Wang J, Kazemi Y, Wang S, Hamidinejad M, Mahmud M B, Pötschke P, Park C B (2020) Enhancing the electrical conductivity of PP/CNT nanocomposites through crystal-induced volume exclusion effect with a slow cooling rate. Composites Part B: Engineering 183:107663.

3. Liang X D, Zhang Z C, Sathisha A, CaiS Q, Bandaru P R (2018) Light induced reversible and irreversible mechanical responses in nanotube-polymer composites. Composites Part B: Engineering 134:39-45

4. Konsta-Gdoutos M S, Batis G, Danoglidis P A, Zacharopoulou A K, Zacharopoulou E K, Falara M G, Shah S P (2017) Effect of CNT and CNF loading and count on the corrosion resistance, conductivity and mechanical properties of nanomodified OPC mortars. Constr. Build. Mater. 147:48-57 
5. Xin X, Yao Z, Shi J, Liang M, Jiang H, Zhang J, Zhang X, Yao K (2020) Rheological properties, microstructure and aging resistance of asphalt modified with CNTs/PE composites. Constr. Build. Mater. 262:120100

6. Goh G L, Agarwala S, Yeong W Y (2019) Directed and on-demand alignment of carbon nanotube: a review toward 3D printing of electronics. Adv Mater Interfaces 6(4):1801318

7. Liu S, Chevali V S, Xu Z G, Hui D, Wang H (2018) A review of extending performance of epoxy resins using carbon nanomaterials. Composites Part B: Engineering, 136 (2018), pp. 197-214

8. Postiglione G, Natale G, Griffini G, Levi M, Turri S (2015) Conductive 3D microstructures by direct 3D printing of polymer/carbon nanotube nanocomposites via liquid deposition modelling, Composites. Part A, 76:110-114

9. Gorrasi G, Bugatti V, Milone C, Mastronardo E, Piperopoulos E, Iemmo L, et al. (2018) Effect of temperature and morphology on the electrical properties of PET/conductive nanofillers composites. Composites Part B: Engineering 135:149-154

10. Faramarzi M., Arabani M., Haghi A.K., Mottaghitalab V. (2015) Carbon nanotubes-modified asphalt binder: preparation and characterization, Int. J. Pavement Res. Technol., 8 (1): 29-37

11. Zhou X., Zhang X., Xu S., Wu S., Liu Q., Fan Z. (2017) Evaluation of thermo-mechanical properties of graphene/carbon-nanotubes modified asphalt with molecular simulation, Mol. Simul., 43 (4): 312-319

12. Ameri M., Nowbakht S., Molayem M., Aliha M.R.M. (2016) Investigation of fatigue and fracture properties of asphalt mixtures modified with carbon nanotubes, Fatigue Fract. Eng. Mater. Struct., 39 (7): 896-906

13. Verma P., Saini P., Malik R.S., Choudhary V. (2015) Excellent electromagnetic interference shielding and mechanical properties of high loading carbon-nanotubes/polymer composites designed using melt recirculation equipped twin-screw extruder, Carbon, 89: 308-317

14. Goli A., Ziari H., Amini A. (2017) Influence of carbon nanotubes on performance properties and storage stability of SBS modified asphalt binders, J. Mater. Civil Eng., 29: 04017070

15. Fang C., Liu P., Yu R., Liu X. (2014) Preparation process to affect stability in waste polyethylene-modified bitumen, Constr. Build. Mater., 54: 320-325

16. Shen B., Li Y., Yi D., Zhai W., Wei X., Zheng W. (2017) Strong flexible polymer/graphene composite films with 3D saw-tooth folding for enhanced and tunable electromagnetic shielding, Carbon, 113: 55-62

17. Neubauer E, Kitzmantel M, Hulman M, Angerer P (2010) Potential and challenges of metal-matrixcomposites reinforced with carbon nanofibers and carbon nanotubes. Compos Sci Technol 70:2228-2236.

18. Gupta A., Choudhary V. (2013) Rheologic and mechanical properties of multiwalled carbon nanotubesreinforced poly(trimethylene terephthalate) composites, J. Mater. Sci., 48:3347-3356

19. Zhong J, Isayev A I, Huang K (2014) Influence of ultrasonic treatment in PP/CNT composites using masterbatch dilution method. Polymer 55:1745-1755.

20. Xu H, Tong X, Zhang Y, Li Q, and Lu W (2016) Mechanical and electrical properties of laminated composites containing continuous carbon nanotube film interleaves. Compos. Sci. Technol. 127:113-118. 
21. Gong M., Yang J., Yao H., Wang M., Niu X., Haddock J.E. (2018), Investigating the performance, chemical, and microstructure properties of carbon nanotube-modified asphalt binder, Road Mater. Pavement, 19 (7):1499-1522

22. Mohamed M. G., Hsiao C-H., Luo F., Dai L., Kuo S-W. (2015) Multifunctional polybenzoxazine nanocomposites containing photoresponsive azobenzene units, catalytic carboxylic acid groups, and pyrene units capable of dispersing carbon nanotubes, RSC Advances; 5(56): 45201-45212 DOI: 10.1039/c5ra07983g

23. Nadernezhad A, Unal S, Khani N, Koc B (2019) Material extrusion-based additive manufacturing of structurallycontrolled poly(lactic acid)/carbon nanotube nanocomposites. Inter. J. of Advanced Manuf. Techn. 102:2119-2132.

24. Wang P., Zhai F., Dong Z.J., Wang L.Z., Liao J.P., Li G.R. (2018) Micromorphology of asphalt modified by polymer and carbon nanotubes through molecular dynamics simulation and experiments: role of strengthened interfacial interactions, Energy Fuels, 32 (2):1179-1187

25. Xu X, Sanei S H R, Steinmetz E, Gohn A, Williams J (2020) Effect of microstructure uncertainty and testing frequency on storage and loss moduli of injection molded MWCNT reinforced polyamide 66 nanocomposites. Polymer Testing 85:106455.

26. Mohamed M. G., Kuo S. W. (2018) Functional Silica and Carbon Nanocomposites Based on Polybenzoxazines, Macromolecular Chemistry and Physics, 220(1):1800306. https://doi.org/10.1002/macp.201800306

27. Samy M. M., Mohamed M. G., Kuo S. W., (2020) Pyrene-functionalized tetraphenylethylene polybenzoxazine for dispersing single-walled carbon nanotubes and energy storage, Composites science and technology,Vol. 199, 2020, 108360 https://doi.org/10.1016/j.compscitech.108360.

28. Fiedler M, Gojny F H, Wichmann M H G, Nolte M CM, Schulte K (2006) Fundamental aspects of nanoreinforced composites. Compos Sci Technol 66:3115-3125.

29. Siddiqui N A, Khan S U, Ma P C, Li C Y, Kim J K (2011) Manufacturing and characterization of carbon fibre/epoxy composite prepregs containing carbon nanotubes. Compos Part Appl Sci Manuf 42:1412-1420.

30. Ma P C, Siddiqui N A, Marom G, Kim J K (2010) Dispersion and functionalization of carbon nanotubes for polymer-based nanocomposites: a review. Compos Part Appl Sci Manuf 41:1345-1367.

31. Muralidharan N, Teblum E, Westover S A, Schauben D, Itzhak A, Muallem M, Nessim G D, Pint C L (2018) Carbon Nanotube Reinforced Structural Composite Supercapacitor. Scientific reports 8:17662.

32. Mahmoodi M J, Vakilifard M (2018) Interfacial effects on the damping properties of general carbon nanofiber reinforced nanocomposites - A multi-stage micromechanical analysis. Compos. Struct. 192:397421.

33. Tapeinos I G, Miaris A, Mitschang P, and Alexopoulos N D (2012) Carbon nanotube-based polymer composites: A trade-off between manufacturing cost and mechanical performance. Compos. Sci. Techno. 72:774-787. 
34. Donga W, Lia W, Shenb L, Sunc Z, Sheng D (2020) Piezoresistivity of smart carbon nanotubes (CNTs) reinforced cementitious composite under integrated cyclic compression and impact.Composite Structures 241:112106.

35. Lecocq H, Garois N, Lhost O, Girard P F, Cassagnau P, Serghei A (2020) Polypropylene/carbon nanotubes composite materials with enhanced electromagnetic interference shielding performance: Properties and modelling. Composites Part B: Engineering 189:107866.

36. Djoudi H, Gelin J C, Barriere T (2015) Experiments and FE simulation for twin screw mixing of nanocomposite of polypropylene/multi-walled carbon nanotubes. Composites Science and Technology 107:169-176.

37. Zhang J, Sahli M, Gelin J C, Khan-Malek C (2014) Rapid-manufacturing of micro-structured devices based on MWCNTs/PP composites by using hot embossing replication process. Microsystem Technologies 20:1919-1924.

38. Tang, C.Y., L.X. Xiang, J.X. Su, K. Wang, C.Y. Yang, Q. Zhang, and Q. Fu.(2008) Largely improved tensile properties of chitosan film via unique synergistic reinforcing effect of carbon nanotube and clay. Journal of Physical Chemistry B 112: 3876-3881.

39. Assouline E., Lustiger A., Barber A.H., Cooper C.A., Klein E., Wachtel E., et al., (2003) Nucleation ability of multiwall carbon nanotubes in polypropylene composites, J Polym Sci, Part B: Polym Phys, 41(5):520527

40. Leelapornpisit W., Ton-That M.-T., Perrin-Sarazin F., Cole K.C., Denault J., Simard B. (2005) Effect of carbon nanotubes on the crystallization and properties of polypropylene, J Polym Sci, Part B: Polym Phys, 43(18):2445-2453

41. Foresta T., Piccarolo S., Goldbeck-Wood G. (2001) Competition between $\alpha$ and $\gamma$ phases in isotactic polypropylene: effects of ethylene content and nucleating agents at different cooling rates, Polymer, 42(3):1167-1176

42. Krache R., Benavente R., López-Majada J.M., Pereña J.M., Cerrada M.L., Pérez E. (2007) Competition between $\alpha, \beta$, and $\gamma$ polymorphs in a $\beta$-nucleated metallocenic isotactic polypropylene, Macromolecules, 40 (19):6871-6878

43. M'Barki A, Bocquet L, Stevenson A (2017) Linking Rheology and Printability for Dense and Strong Ceramics by Direct Ink Writing. Nature, Scientific reports, 7:6017, 1-10.

44. Choi D W and Chang Y H (2012) Steady and Dynamic Shear Rheological Properties of Buckwheat Starch-galactomannan Mixtures. Prev Nutr Food Sci, doi: 10.3746/pnf.2012.17.3.1922012, 17:192-196.

45. Coleman J.N., Cadek M., Ryan K.P., Fonseca A., Nagy J.B., Blau W.J., Ferreira M.S. (2006) Reinforcement of polymers with carbon nanotubes. The role of an ordered polymer interfacial region. Experiment and modelling, Polymer, 47:8556-8561

46. Du F., Scogna R.C., Zhou W., Brand S., Fischer J.E., Winey K.I. (2004) Nanotube networks in polymer nanocomposites: rheology and electrical conductivity, Macromolecules, 37:9048-9055 
47. Acierno S, Barretta R, Luciano R, Marotti de Sciarra F, Russo P (2017) Experimental evaluations and modeling of the tensile behavior of polypropylene/single-walled carbon nanotubes fibers.Composite Structures 17:12-18. 